\title{
Review Article \\ Liquefaction Incidents of Mineral Cargoes on Board Bulk Carriers
}

\author{
Michael C. Munro and Abbas Mohajerani \\ School of Engineering, Civil Engineering, RMIT University, Melbourne, VIC 3000, Australia \\ Correspondence should be addressed to Abbas Mohajerani; dr.abbas@rmit.edu.au
}

Received 31 December 2015; Revised 25 February 2016; Accepted 25 February 2016

Academic Editor: Luigi Nicolais

Copyright (C) 2016 M. C. Munro and A. Mohajerani. This is an open access article distributed under the Creative Commons Attribution License, which permits unrestricted use, distribution, and reproduction in any medium, provided the original work is properly cited.

\begin{abstract}
Liquefaction is a frequently occurring problem taking place when transporting wet granular solid bulk cargoes on board bulk carriers. Liquefaction of a solid bulk cargo can occur when excessive dynamic loading, induced by rough seas and vessel vibrations, is transmitted to the cargo. From 1988 to 2015, there have been 24 suspected liquefaction incidents reported, which resulted in 164 casualties and the loss of 18 vessels. The objective of this study is to investigate the collective causes of liquefaction of solid bulk cargoes on board bulk carriers in order to make recommendations to prevent future incidents from occurring. This was achieved by analysing the seven available investigative reports relating to the incidents, focusing on the key findings and exploring the effect of excess moisture within the cargo. This study has placed significant emphasis on the importance of preventing ingress of water into the cargo during transportation, loading, and storage. Recommendations have been given, based on the key findings from the reports, to reduce the potential for liquefaction incidents to occur.
\end{abstract}

\section{Introduction}

Liquefaction is a frequently occurring problem taking place when transporting wet granular solid bulk cargoes on board bulk carriers [1-3]. Similar to liquefaction of soils during earthquakes [4-7], liquefaction of a solid bulk cargo occurs when excessive cyclic or dynamic loading, induced by rough seas and vessel vibrations, is transmitted to the cargo [8]. Cargoes that are more likely to undergo liquefaction in the holds of bulk carriers are those that contain sufficient amounts of moisture and fine particles [9-12].

Liquefaction, in soil mechanics, is a term used to describe the behaviour of a material that flows in a manner resembling a liquid when subjected to monotonic, cyclic, or shock loading. This behaviour is caused by pore pressures changing within the material, which results in the loss of effective stress and therefore shear strength $[6,13,14]$. Liquefaction does not cease until the loading is reduced causing the shear stresses acting on the mass to be as low as the reduced shear resistance [15]. Although further investigation is needed, some incidents attributed to liquefaction may also be more accurately described as cyclic instability, which is a form of unstable behaviour (strain softening) caused by a succession of dynamic load cycles $[9,16,17]$.

If liquefaction of a solid bulk cargo occurs, it can cause the vessel to list and occasionally capsize [18]. During this study it has been found that, from 1988 to 2015, there have been 24 suspected liquefaction incidents reported, which resulted in 164 casualties and the loss of 18 vessels.

The International Maritime Solid Bulk Cargoes Code (IMSBC Code), published by the International Maritime Organization (IMO), is an internationally recognized code of safe practice to be followed when transporting hazardous solid bulk cargoes on board bulk carriers [19]. In 2011 the IMSBC Code, formally the Code of Safe Practice for Solid Bulk Cargoes (BC Code), was made mandatory under the SOLAS Convention [20]. Included in Appendix 2 of the IMSBC Code are test methods to be followed when a cargo is classified as "Group A" or liquefiable [19]. These test methods include the flow table, penetration, and Proctor/Fagerberg tests, which are described in detail in related publications [11, $21,22]$. The results from these tests provide the shipper with a "safe" moisture content at which the cargo can be loaded without being at risk of liquefying [19]. 
TABLE 1: Major incidents investigated during this study along with the main vessel and incident details [23, 25-30].

\begin{tabular}{|c|c|c|c|c|c|c|c|c|}
\hline $\begin{array}{l}\text { Case } \\
\text { study \# }\end{array}$ & Vessel name & $\begin{array}{c}\text { IMO } \\
\text { number }^{\mathrm{a}}\end{array}$ & $\begin{array}{c}\text { Date of } \\
\text { incident }\end{array}$ & $\begin{array}{c}\text { Casualties/\# } \\
\text { crew }\end{array}$ & Vessel lost & Disembarked & Cargo & $\begin{array}{c}\text { Cargo } \\
\text { (tonnes) }\end{array}$ \\
\hline 1 & Padang Hawk & 9109354 & 26 July 1999 & $0 / 20$ & No & $\begin{array}{l}\text { Kouaoua, New } \\
\text { Caledonia }\end{array}$ & Nickel ore & $\mathrm{N} / \mathrm{A}$ \\
\hline 2 & Hui Long & 9037032 & 20 May 2005 & $0 / 23$ & Yes & $\begin{array}{l}\text { Sungai Pakning, } \\
\text { Indonesia }\end{array}$ & Fluorspar & 5,185 \\
\hline 3 & Jian Fu Star & 8106379 & 27 Oct 2010 & $13 / 25$ & Yes & Obi Island, Indonesia & Nickel ore & 43,000 \\
\hline 4 & $\begin{array}{c}\text { Nasco } \\
\text { Diamond }\end{array}$ & 9467861 & 09 Nov 2010 & $22 / 25$ & Yes & $\begin{array}{l}\text { Kolonodale, } \\
\text { Indonesia }\end{array}$ & Nickel ore & 55,150 \\
\hline 5 & Hong Wei & 9230139 & 3 Dec 2010 & $10 / 24$ & Yes & $\begin{array}{l}\text { Kolonodale, } \\
\text { Indonesia }\end{array}$ & Nickel ore & 40,000 \\
\hline 6 & $\begin{array}{c}\text { Trans } \\
\text { Summer }\end{array}$ & 9615468 & 14 Aug 2013 & $0 / 21$ & Yes & Subaim, Indonesia & Nickel ore & 54,067 \\
\hline 7 & Bulk Jupiter & 9339947 & $02 \operatorname{Jan} 2015$ & $18 / 19$ & Yes & Kuantan, Malaysia & Bauxite & 46,400 \\
\hline
\end{tabular}

${ }^{\mathrm{a}}$ The IMO number is a distinctive reference number of a vessel [31].

This "safe" moisture content is known as the transportable moisture limit (TML) and its inferred definition is "the maximum gross water content that a liquefiable cargo may contain without being at risk of liquefying while being transported in a bulk carrier" [19]. The flow moisture point (FMP) is also determined using two of the three methods stated in the IMSBC Code. The TML is $90 \%$ of the FMP [19]. Along with these test methods, other policies and procedures are included to reduce the occurrence of liquefaction incidents and ensure liquefiable cargoes do not get loaded on a bulk carrier if it exceeds its TML.

One final method in the IMSBC Code used to determine if a cargo is potentially liquefiable is the "Can Test." If a Master has doubts in regard to the appearance or condition of the material, a simplified in situ testing method for providing a rough idea on the possibility of flow may be carried out by half filling a cylindrical vessel of about 1 litre capacity with a sample of the cargo and striking it against a hard surface at least 25 times. If free moisture appears on the surface of the sample, additional laboratory tests should be conducted [19, 23].

Some other physical properties that influence the liquefaction potential of "Group A" cargoes are the particle size, void ratio, degree of saturation, hydraulic conductivity, and pore air/water pressure characteristics [9-11]. Additionally, some system variables is the induced cyclic loading, drainage conditions, and rate of loading. The moisture content is considered the major factor regarding the liquefaction potential of "Group A" cargoes. It is noted that all the test methods given in the IMSBC Code use the moisture content of the cargo as a variable that can be monitored and adjusted accordingly to prevent cargoes from liquefying. Other physical properties of the cargo are not considered changeable to prevent liquefaction of the cargoes [19]. This is because the majority of cargoes being transported on bulk carriers are considered products and therefore their physical properties are more or less unalterable.

The objective of this study is to investigate the collective causes of liquefaction of solid bulk cargoes on board bulk carriers in order to make recommendations to prevent future incidents from occurring. This will be achieved by analysing the available investigative reports relating to the incidents, focusing on the key findings and exploring the effect of excess moisture within the cargo.

\section{Case Studies}

In order to make recommendations to prevent future liquefaction incidents from occurring, investigation reports will be utilized to summarize seven incidents including the conclusions and key findings. These seven investigation reports are the only publicly available reports of suspected liquefaction incidents from 1988 to 2015 . The list given in Table 1 shows the major incidents that are investigated during this study along with the main vessel and incident details.

It is noted that the terms "sea state" and "wind force," given herein, are stated using the Douglas and Beaufort scales, respectively [24]. All the case study summaries and conclusions presented in Section 2 have been obtained from their respective investigation reports [23, 25-30]. By summarizing and analysing these incidents, we hope to determine trends or similarities that may be causing these incidents to occur.

2.1. Case Study 1: Padang Hawk. Built in 1995, the Singapore flag Padang Hawk (IMO: 9109354) is a handymax bulk carrier with a summer deadweight of 46,635 tonnes [32]. The vessel, which has a length of $190 \mathrm{~m}$, breadth of $31 \mathrm{~m}$, and summer draught of $12 \mathrm{~m}$, has five cargo holds serviced by four onboard cranes [25]. At the time of producing this report the Padang Hawk, now Panama flag Tong Ji Men, is still in active service [33]. The Padang Hawk along with its hold and tank layout can be seen in Figures 1 and 2.

2.1.1. Summary of Incident. On 17 July 1999 at 1224, the Padang Hawk arrived at the port of Kouaoua, New Caledonia, seen in Figure 3, to begin loading a cargo of nickel ore from shore barges. Loading commenced at 1440 and was completed on 23 July by 2140 . Each day during loading, soundings were taken to record if any water was present in the cargo holds. Although no bilge water was recorded during these soundings, the crew noticed that some of crane "grabs" of the cargo 


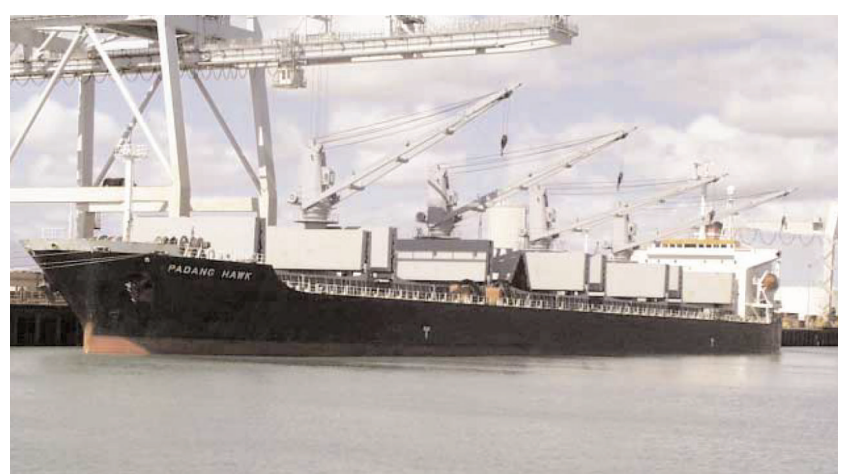

Figure 1: The Padang Hawk [25].

had water running from them as they were transferred from the barges into the cargo holds of the bulk carrier [25].

The Padang Hawk departed Kouaoua at 2307 on 23 July on a north-westerly course along the coast of New Caledonia. At 1700 on 24 July, the ships logbook shows that the bilges of all cargo holds were pumped dry while the vessel was rolling heavily in south-easterly swells. Just before 2400 on the same day, the Padang Hawk altered course north of Récifs d'Entrecasteaux. The vessel was rolling and pitching heavily when the wind was noted as being east-south-east and at force 5 , and the sea was described as rough as the Padang Hawk sailed west towards Townsville, Australia [25].

At 0900 on 25 July and 0830 on 26 July, the bilges in all holds were again pumped. The rough conditions caused the vessel to roll and pitch heavily, particularly from 1600 onwards on 25 July. At noon on 26 July, the Padang Hawk was about 100 nautical miles of Marion Reef, as seen in Figure 4. During the afternoon, the wind strength was logged at force 5 with regular notations in the logbook concerning the ship's heavy rolling. Throughout the day, from time to time, seas broke over the deck and hatch covers. By 2000, the wind was logged at force 6-7 and the vessel was rolling heavily. The hold bilges were pumped at 2000 and again at 2100 [25].

A little before 2200 the Padang Hawk suddenly developed a 15-degree list to port. After reducing speed and altering the course to bring the wind and sea onto the port quarter, crew were sent to check the hatches and the state of the main deck. After noting that nothing was out of place, the crew opened access hatches to each of the holds. They found that the cargo of nickel ore in all the holds, except hold number 5 , had settled and shifted to port. The cargo in the first three holds appeared to be semiliquid, "like melted ice cream," as one of the crew described it. Two images of the nickel ore in hold number 1 of the Padang Hawk can be seen in Figure 5 [25].

After using ballast to try to correct the list, a message was sent to the Australian Maritime Safety Authority (AMSA) via the ships agent in Townsville noting the condition of the ship and actions taken and reporting that the cargo had liquefied [25].

By early morning, the list had been reduced to about 5 degrees by using the vessel's double bottom ballast tanks, which was recommended by the owners. The strong wind and heavy swell continued and seas broke regularly over the vessel's quarter. The cargo hold bilges were pumped at regular intervals throughout the day [25].

Due to the consistently rough weather, at noon on 27 July, the Master decided to maintain the course with the wind astern. This course took the Padang Hawk directly towards Grafton Passage. In the early hours of 28 July, the ship was approaching Grafton Passage. By 0400, it was safely in the calmer waters inside the Great Barrier Reef and later that afternoon the vessel anchored off Townsville. Once a pilot boarded, the Padang Hawk was safely navigated and docked at Townsville by 1930 [25].

2.1.2. Investigation Conclusions. Investigations into the incident started immediately after the Padang Hawk arrived at Townsville, Australia. The following are the main conclusions from the investigation into the incident involving the Padang Hawk [25].

(1) The cargo was loaded with excessive moisture content.

(2) The vessel was subjected to heavy seas, which led to the cargo changing state from a solid to a viscous liquid in 4 of the 5 holds.

(3) Insufficient knowledge of the characteristics of nickel ore as a cargo and its propensity to become fluid when the moisture content is high and it is subjected to sufficient physical stress.

(4) There is no test to specifically ascertain the transportable moisture limit (TML) of nickel ore.

(5) The owners/agent of the vessel did not include in Master's voyage instructions the relevant information pertaining to the cargo moisture content, flow tests, and Master's right to refuse to load the cargo under the terms of the agreement between the buyer, Queensland Nickel Pty Ltd. (QNPL), and the cargo sellers.

(6) The ore seller did not provide the Master with the agreed data pertaining to the cargo's moisture content and flow tests as required by the SOLAS Convention.

(7) The Master loaded the nickel ore without insisting on the provision of the data concerning the moisture content and flow tests.

(8) The mined nickel ore was stockpiled in areas open to the ingress of rainwater.

(9) The agreement between QNPL and the seller did not stipulate a reasonable, maximum, acceptable moisture content, based on the nickel ore's ability to be carried safely by sea.

Additionally, the flow table test, which is used to determine the TML of coal and ore concentrates [19], was performed on the cargo of nickel ore after the incident and the moisture content of the cargo was found to exceed the TML determined by the test [25].

2.2. Case Study 2: Hui Long. Built in 1999, the Hong Kong flag Hui Long (IMO: 9037032) was a handysize bulk carrier with a summer deadweight of 16,113 tonnes [32]. The vessel, which 

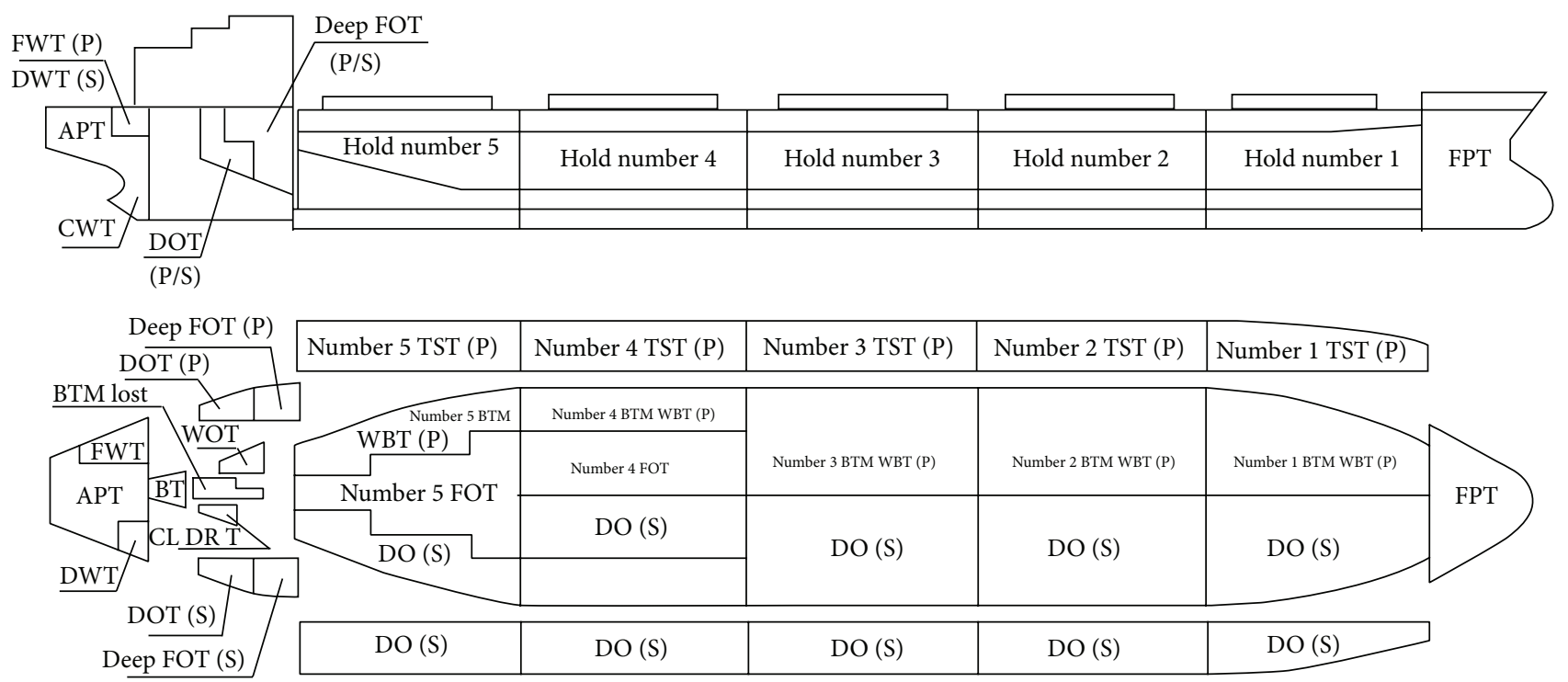

Figure 2: Padang Hawk and Jian Fu Star hold and tank layout [23, 25].

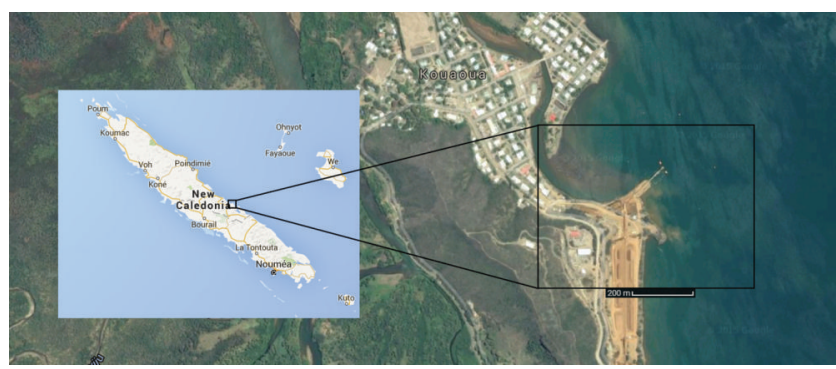

Figure 3: Port of Kouaoua, New Caledonia (source: Google Maps).

had a length of $158 \mathrm{~m}$ and breadth of $23 \mathrm{~m}$ had four cargo holds serviced by three on-board cranes [29]. The Hui Long can be seen in Figure 6.

2.2.1. Summary of Incident. On 1 May 2005, the Hui Long arrived in Hong Kong from China and was loaded with 5,185 tonnes of fluorspar in hold number 1 and the lower part of hold number 3, as seen in the stowage plan in Figure 7. Loading was carried out by grabs from the barges that were moored alongside the vessel [29].

According to the weather and crew reports, there had been slight showers on the day of loading, which did not impair the loading of the cargo. After completion, samples from the two holds were taken and a certificate of moisture content was issued. The certificate indicated that the moisture content of the fluorspar cargo was at $9.8 \%$. The certificate did not provided the details of the transportable moisture limit (TML) of the fluorspar [29].

The next day the vessel sailed to Singapore to unload a cargo of aluminium ingots and steel angle bars where it was reported that there had been intermittent rain showers during the cargo operation and that the crew would close hatch covers numbers 2, 3, and 4 when raining. The vessel departed Singapore on 11 May for Sei Pakning, Indonesia, to load a cargo of wood pulp. Again, during loading, it was reported that there had been occasional rain showers and the ship's crew had to close hatch covers numbers 2,3 , and 4 during the rain, as wood pulp cargo is susceptible to rainwater. After loading was completed on 14 May, the Hui Long departed Sei Pakning, Indonesia, for India loaded with a deadweight of 11,244 tonnes including the 5,185 tonnes of fluorspar. The vessel was upright and in normal working condition on its departure and it was indicated that the vessel had no major structural problems [29].

On 18 May, the Hui Long was proceeding off Sumatra on a westerly course. The weather was fine with moderate sea and south-westerly wind at force 5 . Occasional moderate rolling of vessel movement was experienced. According to the Master, ship movement was normal and there was no severe rolling during the voyage [29].

On 18 May at approximately 1535, the Hui Long suddenly developed a 15-degree list to port. The bridge navigating officer stated that the vessel was navigating normally with no irregularities and rolled moderately approximately 10 degrees to both sides before the list. After reporting the incident, the Master informed the engineers to upright the vessel by filling the starboard double bottom tanks. The crews were not able to upright the vessel with ballasting due to the severe listing [29]. An image of the Hui Long listing severely to port can be seen in Figure 8.

At 1602, as the list worsened to 40 degrees to port, the Master decided to abandon the vessel. At this time, the port deck edge of the vessel was immersed under the sea. A nearby container vessel and the management company in China were made aware of the situation [29].

The nearby container vessel successfully rescued all crewmembers from the water and the life rafts. A salvage tug arrived at the scene the following day but the vessel sank 49 hours and 43 nautical miles north-east of the initial listing position. There were no casualties reported in the incident [29]. 


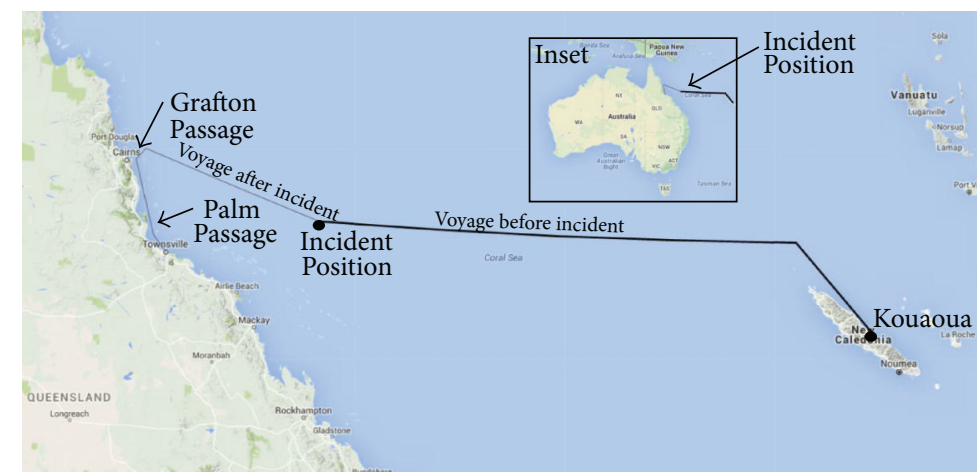

Figure 4: Padang Hawk's approximate voyage from Kouaoua, New Caledonia to Townsville, Australia [25].
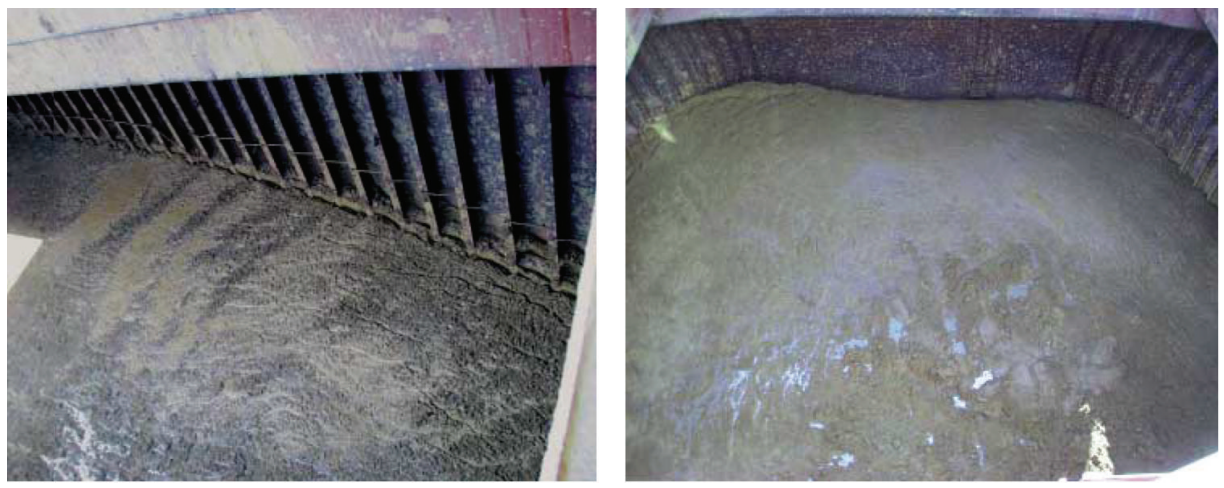

Figure 5: Images of the nickel ore in hold number 1 of the Padang Hawk [25].

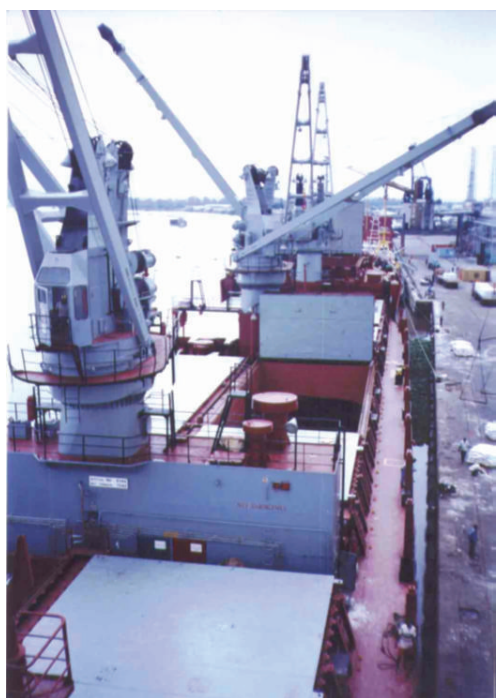

Figure 6: The Hui Long [29].

2.2.2. Investigation Conclusions. The following are the main conclusions from the investigation into the sinking of the Hui Long [29].

(1) The exact cause of the sinking of "Hui Long" could not be established.
(2) After investigating the probable causes of the accident, it is believed to be the liquefaction of the fluorspar cargo inside holds numbers 1 and 3. The flow state of the fluorspar cargo might have caused the vessel to list, capsize, and sink.

(3) The Master appeared to have not followed the company's cargo safety manual for loading a bulk cargo that may liquefy by accepting on board for shipment of fluorspar cargo with the moisture content higher than the stipulated $8 \%$.

(4) The shipper has failed to provide the TML of the fluorspar cargo before the shipment as required by the Merchant Shipping (Safety) (Carriage of Cargoes) Regulation and the BC Code, while a norm of $10 \%$ TML for bulk fluorspar was used by the shipper without documentation support of any laboratory test. As such it is possible that the fluorspar cargo at moisture content of $9.8 \%$ had exceeded the actual TML.

(5) The amount of sample taken by the survey firm would not be sufficient for a proper determination of moisture content as far as the BC Code is concerned.

2.3. Case Study 3: Jian Fu Star. Built in 1982, the Panama flag Jian Fu Star (IMO: 8106379) was a handymax bulk carrier with a deadweight of 45,107 tonnes [32]. The vessel, which had a length of $190 \mathrm{~m}$, breadth of $31 \mathrm{~m}$, and summer draught of $11 \mathrm{~m}$, had five cargo holds serviced by four cranes [23]. 


\begin{tabular}{|c|c|c|c|c|c|c|c|}
\hline \multicolumn{4}{|c|}{ Hatch number 4} & \multicolumn{2}{|c|}{ Hatch number 3} & Hatch number 2 & Hatch number 1 \\
\hline Melanie & \multicolumn{2}{|c|}{$\begin{array}{c}\text { BTN MB102- } \\
01[?] \\
\text { Sungai Pakning[?] } \\
150 \# / 300\end{array}$} & \begin{tabular}{|} 
BTN MB102- \\
01 \\
Sungai Pakning- \\
Mumbai \\
Melanie \\
$100 \# / 200$ \\
MT
\end{tabular} & $\begin{array}{l}\frac{\text { Mumbai EX }}{\text { Singapore }} \\
\frac{\text { Machinery and }}{\text { pipes }} \\
\text { 36 P'KGS } \\
45.312 \mathrm{MT}\end{array}$ & $\begin{array}{l}\frac{\text { BTN MB102-03 }}{\text { Sungai Pakning-Mumbai }} \\
\text { Balallpur } \\
460 \text { units } \\
920 \text { tons }\end{array}$ & $\begin{array}{c}\frac{\text { BTN MB102-03 }}{\text { Sungai Pakning-Mumbai }} \\
\text { Balallpur } \\
607 \text { units } \\
1214 \text { tons }\end{array}$ & $\begin{array}{l}\frac{\text { Kandla }}{\text { Fluorspar }} \\
450 \text { MT } \\
\text { in bulk }\end{array}$ \\
\hline$[?=$ ill & legible] & BT & $\begin{array}{l}\frac{\text { N MB102-03 }}{\text { gai Pakning-Mumbai }} \\
\text { Balallpur } \\
235 \text { units } \\
470 \text { tons }\end{array}$ & \multicolumn{2}{|c|}{$\begin{array}{l}\frac{\text { Kandla }}{\text { Fluorspar }} \\
\text { 4685.358 MT } \\
\quad \text { in bulk }\end{array}$} & $\begin{array}{c}\text { BTN MB102-03 } \\
\text { Sungai Pakning-Mumbai } \\
\text { Balallpur } \\
948 \text { units } \\
1896 \text { tons }\end{array}$ & \\
\hline
\end{tabular}

Figure 7: Hui Long's cargo stowage plan on departure from Sei Pakning [29].

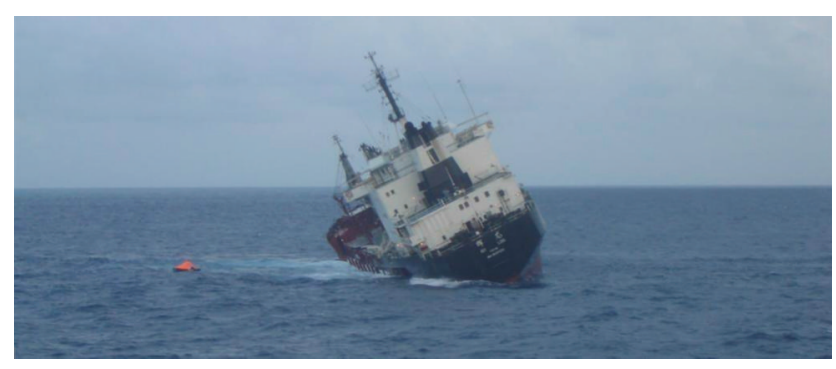

FIGURE 8: Hui Long listing severely to port after suspected liquefaction of the cargo of Fluorspar [29].

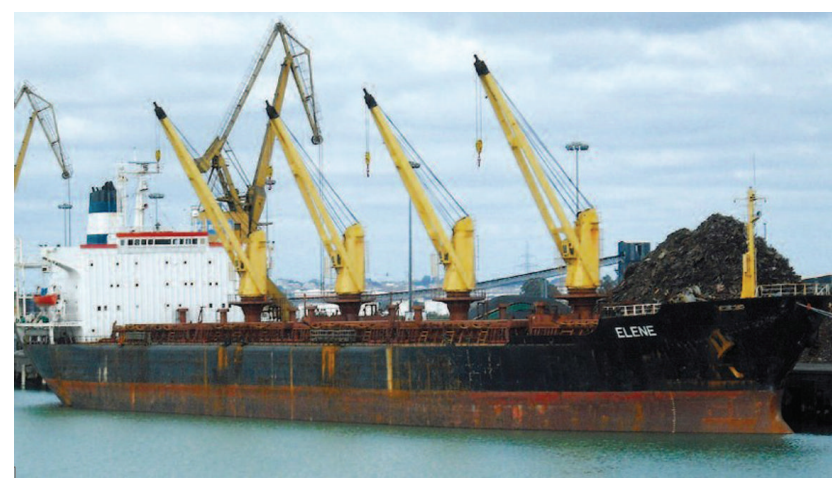

FIgURE 9: The Jian Fu Star [35].

The Jian Fu Star, as seen in 2008 as Elene [34], along with the hold and tank layout can be seen in Figures 9 and 2 .

2.3.1. Summary of Incident. On 16 October 2010 at approximately 1900, the Jian Fu Star arrived at an Obi Island port in Indonesia, one of which can be seen in Figure 10. Loading commenced on 17 October at 0200 and was completed on 20 October by approximately 1400 . The Master and Chief Officer noted that the cargo was dry in appearance and to the touch, similar to previous loadings condition. Due to the visually dry appearance of the cargo, the Master and Chief Officer did not carry out any tests to determine its moisture content [23].

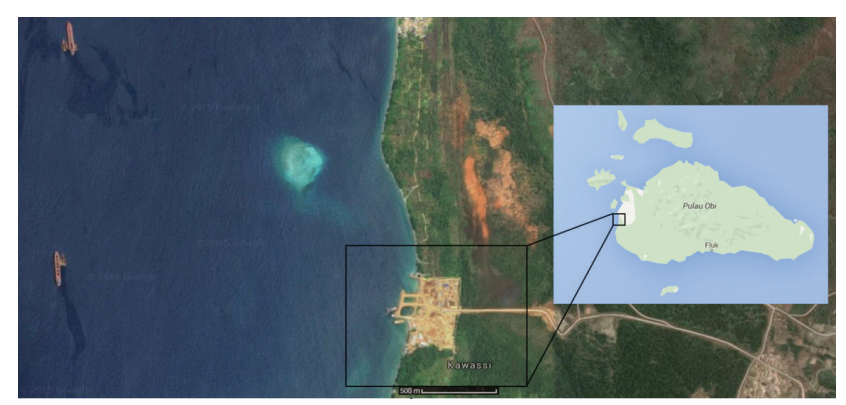

Figure 10: Port of Kawassi, Obi Island, Indonesia (source: Google Maps).

The stowage plan for the Jian Fu Star for this voyage can be seen in Figure 11.

The vessel loaded 23,800 tonnes of nickel ore continuously depending on the inflow of barges and halting during periods of occasional showers. After the Master noted that the moisture content of the nickel ore was less than the shipper's earlier declaration, the Jian Fu Star departed Obi Island, Indonesia, on the 20 October at approximately 1800 bound for Lazhou, China [23].

During loading, there were no reports of damage to the bulk carrier by either the barges or grab cranes. The journey from Obi Island to just off Lazhou was uneventful and the weather was reported to be fine with calm sea states. On 26 October at approximately 1000, as the vessel continued towards Lazhou, the wind shifted to a strong northerly with a force of 5 to 6 . By 1400 the wind had increased to force of 7 to 8 and sea conditions worsened causing the vessel to pitch heavily and roll moderately [23].

On 27 October at approximately 0700, as the sea remained rough and swell heavy, the vessel listed suddenly 5 degrees to port and did not upright itself. Procedures began to try to upright the vessel by reducing the port and increasing the starboard tank ballast along with transferring fuel from port to starboard. Even after these measures were implemented, the vessel's list increased to 10-degree port [23]. 


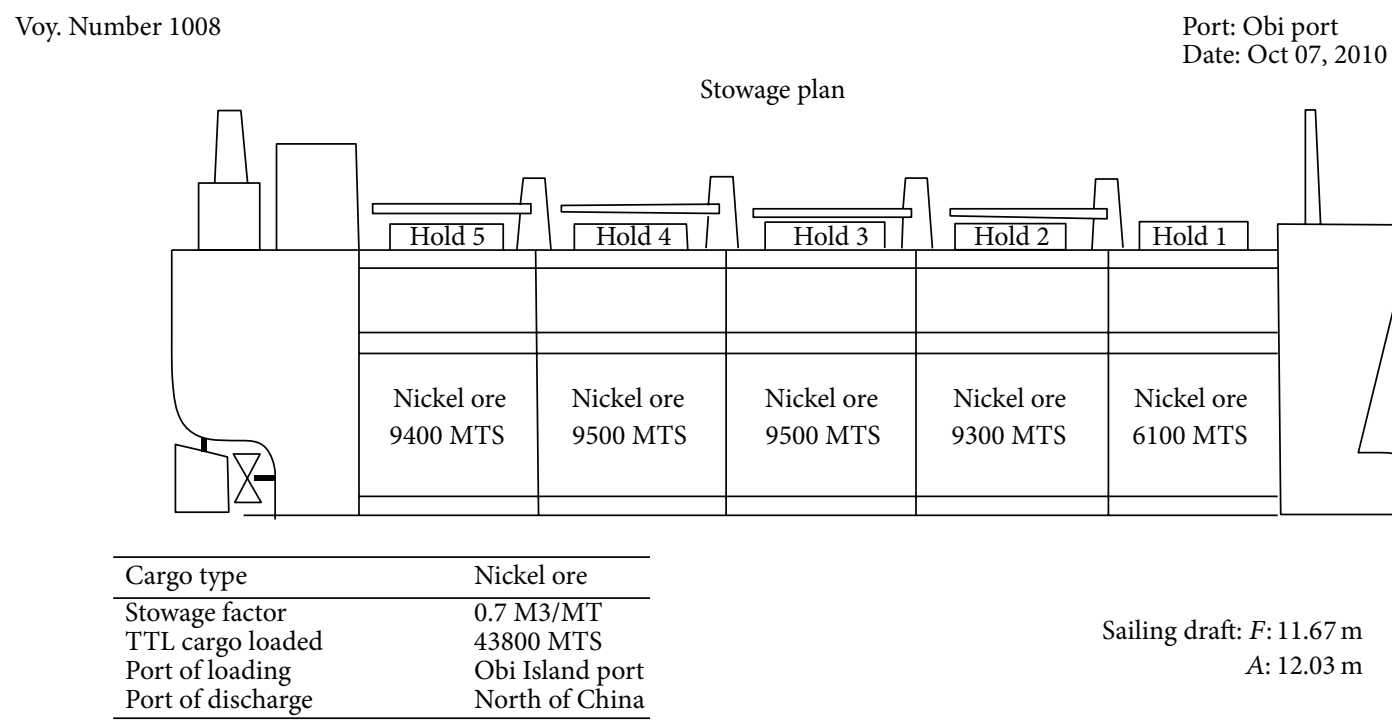

FIgURE 11: Stowage plan for the Jian Fu Star [23].

At this time, the general alarm was raised and the Master notified the company in charge. During this time, the vessel's list had increased dramatically to where the port deck was level with the sea. Due to the inevitable capsizing of the vessel, a distress signal was activated and the abandon ship alarm was sounded. The vessel sank within a 20-minute period from the initial list. Of the 25 crewmembers on board the Jian Fu Star, 12 were rescued [23].

2.3.2. Investigation Conclusions. The following are the main conclusions from the investigation into the sinking of the Jian Fu Star [23].

(1) The exact cause of the sinking of Jian Fu Star could not be established with absolute certainty as the vessel had completely sunk.

(2) The mined nickel ore was stockpiled in areas open to the ingress of rainwater.

(3) The cargo was loaded with suspected excessive moisture content.

(4) The vessel was subjected to heavy seas, which led to the cargo changing state from a solid to a viscous liquid in all of its 5 holds.

(5) Insufficient knowledge of the characteristics of nickel ore as a cargo and its propensity to become fluid when the moisture content is high and it is subjected to sufficient physical stress.

(6) It is highly believed the accident was a result of liquefaction of the nickel ore inside the cargo holds that caused the sudden list, capsize, and sinking of the Jian Fu Star.

(7) There is no test to specifically ascertain the transportable moisture limit (TML) of nickel ore.

(8) The owners/manager of the vessel did not have clear instruction on the care and handling of such cargoes as specified in its Safety Management System, especially relating to the procedures in accepting shipper's laboratory certificate, self-basic testing of the cargo moisture content, and the procedures in Master's right to refuse to load the cargo under the terms of the agreement between the Chinese buyer and the cargo sellers.

(9) The ore seller did provide the Master with data pertaining to the cargo's moisture content and flow tests as required by SOLAS, but with respect to accuracy and authenticity of the laboratory data, this was very much in doubt.

(10) The Master and Chief Officer appeared to have not followed strictly the IMSBC Code's guideline and recommendation of carrying a basic "Can Test" to determine and compared the stated cargo specification declaration supplied by the shipper.

(11) The shipper might have failed to provide accurately the TML of the nickel ore before the shipment as required by the IMSBC Code.

2.4. Case Study 4: Nasco Diamond. Built in 2009, the Panama flag Nasco Diamond (IMO: 9467861) was a handymax bulk carrier with a summer deadweight of 56,893 tonnes [32]. The vessel, which had a length of $186 \mathrm{~m}$, breadth of $32 \mathrm{~m}$, and summer draught of $13 \mathrm{~m}$, had five cargo holds serviced by four on-board cranes [26]. The Nasco Diamond can be seen in Figure 12.

2.4.1. Summary of Incident. On 18 October 2010 at 2130, the Nasco Diamond arrived at Kolonodale, Central Sulawesi, Indonesia, seen in Figure 13, to begin loading a cargo of nickel ore from shore barges, similar to what is seen in Figure 14. Loading operations commenced at 2245 on 19 October. The same day, the flow table test was carried out on a sample of the cargo that was to be loaded on the Nasco Diamond. 


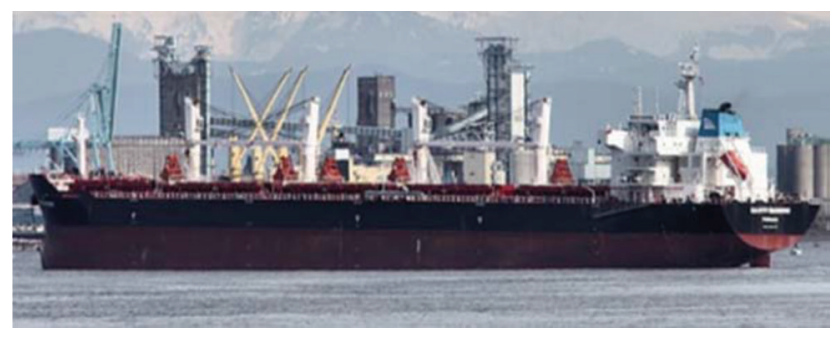

Figure 12: The Nasco Diamond [26].

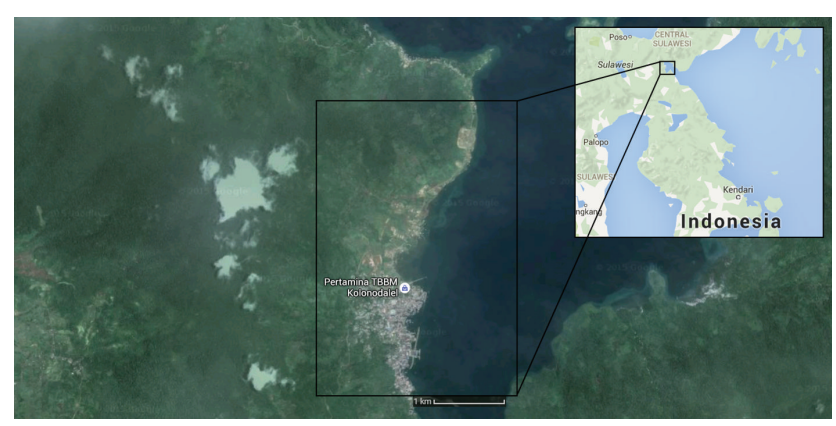

FIGURE 13: Port of Kolonodale, Central Sulawesi, Indonesia (source: Google Maps).

The representative sample that was tested was taken two days prior to 16 October [26].

The results of the test showed that the moisture content at time of sampling was $30.08 \%$ with a flow moisture point of $37.00 \%$ and resulting transportable moisture limit of $33.25 \%$. It was noted that the barges carrying the nickel ore had no protection from the "time to time, pouring" rain during the passage and loading and that there was no sample taken for the determination of moisture content after 16 October [26].

During loading, the Master was unsatisfied with the condition of the nickel ore cargo that was being brought to the vessel by the barges. On 2 November, a "note of protest" was prepared and within stated, "We find the cargo in [the 12th barge] is very wet and contains plenty of water. In view of the above fact, $I$, the Master of the $M V$ 'Nasco Diamond', regret to submit this notice in advance to reject to receive this cargo, the ship, owner is not responsible for any loss." [26]. Photographs were taken at this time and can be seen in Figure 15. The "note of protest" was more or less ignored as the cargo was allowed to be loaded being wet [26].

On 4 November at 1230, after the loading of 55,150 tonnes of nickel ore was complete, the Nasco Diamond departed Kolonodale, Indonesia. The stowage plan can be seen in Figure 16. The vessel was reported to be in normal working condition at the time of its departure [26].

The journey was uneventful until 9 November at 1111 when the Master reported to his respective supervisor that the vessel was listing 3 degrees to port. After inspections of all five holds, slurry was observed. It was noted that slurry was observed in the aft section of hold number 1, in the aft section of hold number 4 (approximately 50 to $60 \mathrm{~cm}$ depth), and in the aft section of hold number 5 (approximately 20 to $40 \mathrm{~cm}$

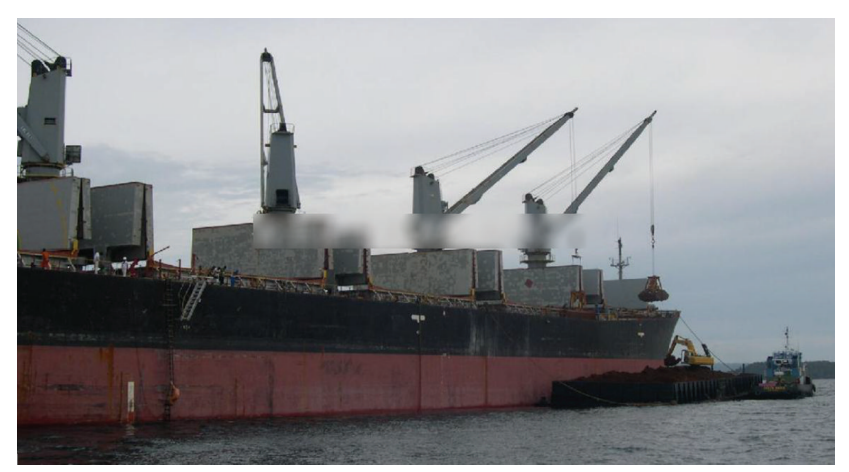

FIGURE 14: Loading operation at Kolonodale, Indonesia, similar to that of the Nasco Diamond and Hong Wei [26].

depth). Holds numbers 2 and 3 were dry with no formation of slurry [26].

At this time, the wind was north-easterly with force of 6 to 7 , the sea was 3 meters in height and the vessel was rolling between 0 degrees and 7 degrees on the port side. The Master reported that his intent was to use ballast to try to correct the vessel's list but was instructed to wait for further instructions [26].

At 1137, the Master was contacted by his respective supervisor, whom had gathered the company's emergency response team, and it was suggested that he adjusted his sailing course to head windward, so as to minimize the rolling of the vessel. It was also suggested he scooped the slurry into oil drums and, with a submersible pump placed in the drum, attempted to pump the slurry out of the vessel's holds. Following that, the Master was also instructed to take the sounding of all the ballast and oil tanks and to get the assistance of all crew on board to assist in scooping the slurry except for those on duty [26].

At 1217, the captain reported that the removal of the slurry was progressing and going well. At 1314, the Master reported that the submersible pump had been placed in a bamboo basket and was directly pumping the slurry from top of the cargo. At this time, the Master also reported that the surface of the cargo in the respective holds was uneven and all water from the bilges had been drained out [26].

Sometime between 1650 and 1720, after reporting that the vessel was now rolling between 5 degrees port to 2 degrees starboard, the captain reported that the situation is rather stable. From 1817 to 1825 , the Master reported that the vessel was swaying uniformly about 2.5 degrees and the vessel was in stable condition with the sea state reduced to 2 meters [26].

At 2030, the emergency response team called the Master but there was no answer. From 2030 to 2041, the emergency response team kept calling while also checking the status of the vessel using the available satellite tracking. At 2230, after continuing calls went unanswered and tracking was lost, the emergency response team began search and rescue procedures [26].

On 10 November at 0951, the emergency response team was notified that a rescue plane located an oil slick on the sea surface and located two life rafts. At 2330, they were also notified that three life rafts were located by other rescue planes. 

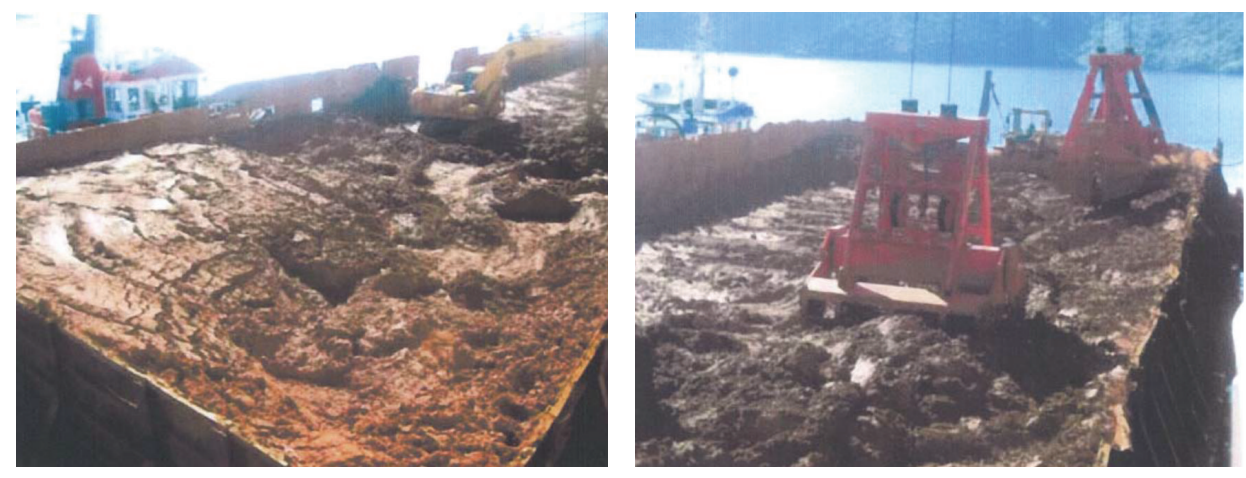

FIGURE 15: Photographs submitted to the head office by the Master of the condition of the nickel ore cargo at the time of loading at Kolonodale, Indonesia [26].

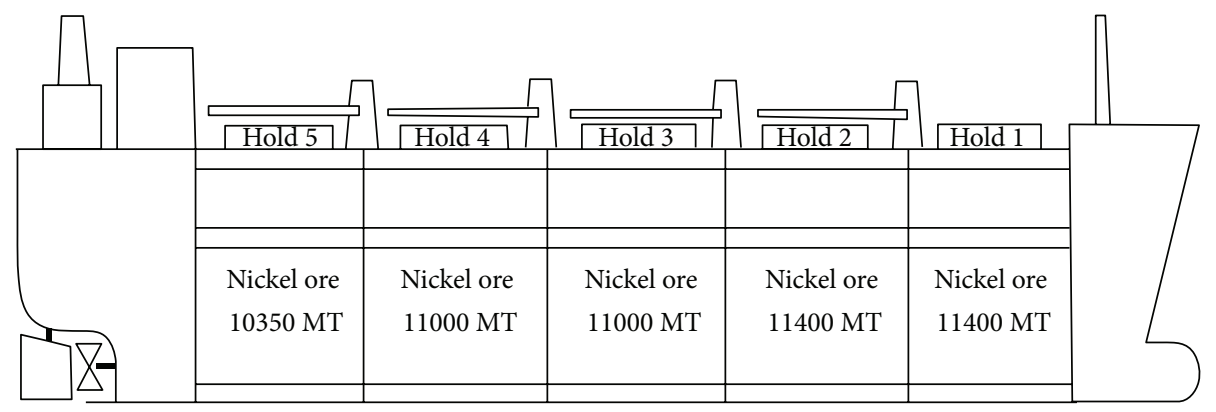

Figure 16: Nasco Diamond stowage plan [26].

The name on the life rafts could not be read at the distances they were seen but it was confirmed that they contained no survivors. On 11 November rescue ships from Taiwan and Japan found and rescued three crewmembers and retrieved two dead bodies. The rescue operations ceased on 13 November at 2200 leaving 22 crewmembers deceased or missing [26].

2.4.2. Investigation Conclusions. The following are the main conclusions from the investigation into the sinking of the Nasco Diamond [26].

(1) The exact cause of the sinking of Nasco Diamond could not be established.

(2) The cargo as presented for loading was not in accordance with the Code of Safe Practice for Solid Bulk Cargoes (IMSBC Code). The cargo was loaded with excessive moisture content as evident from the damp cargo loaded from the barge and Master's "note of protest.”

(3) The IMSBC Code was not adhered to as stated in Appendix 1.

(a) Under "Carriage," "the appearance of the surface of the cargo shall be checked regularly during voyage. If free water above the cargo or fluid state of the cargo is observed during voyage, the Master shall take appropriate actions to prevent cargo shifting and potential capsize of the ship and give consideration to seeking emergency entry into a place of refuge."

(b) Under "Weather Precautions," the moisture content of the cargo is more than the TML during voyage.

(4) There is insufficient knowledge regarding the characteristics of nickel ore as a cargo and its propensity to become fluid when the moisture content is high and it is subjected to sufficient physical stress. The vessel was subjected to heavy seas, which led to the cargo changing state from a solid to a viscous liquid in 3 of the 5 holds.

(5) On completion of loading, there was no sample taken to test to specifically ascertain the "transportable moisture limit" of the nickel ore. The ore seller did not provide the Master with the agreed data pertaining to the cargo's moisture content and flow tests as required by SOLAS and BC Code (IMSBC Code).

(6) No evidence to indicate whether the owners/agents of the vessel have included, in the Master's voyage instruction, the relevant information pertaining to the cargo moisture content, flow tests, and Master's right to refuse to load the cargo under the terms of the agreement between the cargo buyer and cargo seller.

(7) The Master loaded the nickel ore without insisting on the provision of the data concerning the moisture 


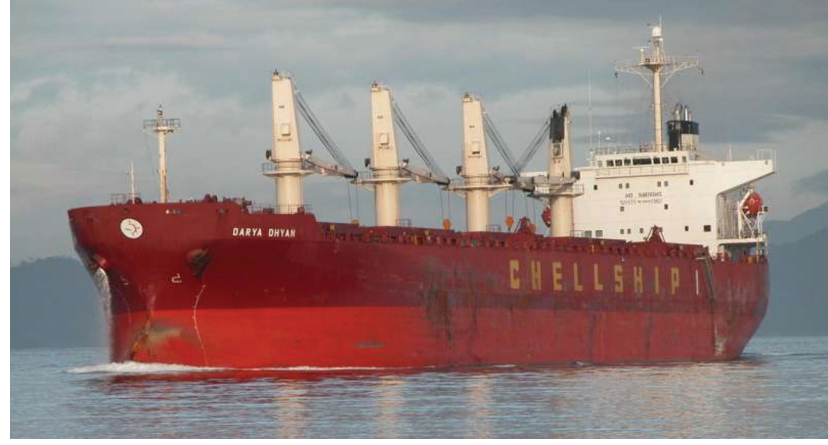

Figure 17: The Hong Wei (source: Silvio Roberto Smera) [37].

content and flow tests of the cargo on board even after physically seeing the ore arriving in wetted condition.

(8) The mined nickel ore was stockpiled and transported in ways that allowed the ingress of rainwater.

(9) The vessel's stability should have been calculated for the loaded condition leaving Kolonodale, Indonesian, and subsequently checked prior to the pumping of ballast into the topside and double bottom tanks to correct the list, if any.

(10) After investigation the probable causes of the accident, it is believed to be the liquefaction of the nickel ore cargo inside holds numbers 1,4 , and 5. The flow state of the nickel ore cargo might have caused the vessel to list, capsize, and sink.

2.5. Case Study 5: Hong Wei. Built in 2001, the Panama flag Hong Wei (IMO: 9230139) was a handymax bulk carrier with a deadweight of 50,149 tonnes [32]. The vessel, which had a length of $181 \mathrm{~m}$, breadth of $32 \mathrm{~m}$, and draught of $12 \mathrm{~m}$, had five cargo holds serviced by four on-board cranes [27]. The Hong Wei, as seen in 2006 as the Darya Dhyan [36], can be seen in Figure 17.

2.5.1. Summary of Incident. On 6 November 2010 at 1820, the Hong Wei arrived at Kolonodale, Central Sulawesi, Indonesia, seen in Figure 13, to begin loading a cargo of 48,900 tonnes of nickel ore from shore barges, similar to what is seen in Figure 14 [27].

During loading, the Chief Engineer recalled that it rained during two occasions and the cargo loading operations were stopped during this time. Additionally, he could not recall if during inspections of the cargo by the Chief Officer it was found to be in dry conditions or not.

On 4 November, prior to the arrival of the Hong Wei at Kolonodale, Indonesia, a flow table test was carried out to determine the transportable moisture limit of the nickel ore cargo. The results of the test showed that the moisture content at time of sampling was $31.50 \%$ with a flow moisture point of $37.00 \%$ and resulting transportable moisture limit of $33.25 \%$.

Loading operations were completed on 27 November at approximately 1800 and the vessel departed Kolonodale, Indonesia, for Lanshan, China, on the 28 November at
TABle 2: Cargo distribution of the Hong Wei when departing Kolonodale, Indonesia [27].

\begin{tabular}{lc}
\hline Cargo hold number & $\begin{array}{c}\text { Quantity of nickel } \\
\text { ore (tonnes) }\end{array}$ \\
\hline 1 & 8,600 \\
2 & 10,100 \\
3 & 9,700 \\
4 & 10,100 \\
5 & 10,400 \\
\hline Total & 48,900 \\
\hline
\end{tabular}

approximately 0600 . The cargo distribution of the Hong Wei can be seen in Table 2 [27].

The weather at the time of departure was fine with winds of force 3 and slight seas. It was reported that from 28 November to 2 December, the wind force gradually increased to force 4 . The interviewed Bosun reported that every day, at around 1500 to 1600 , he usually checked the cargo holds and that everything seemed normal [27].

On 3 December at approximately 1300, the Chief Engineer felt a hard shock and reported that the vessel moved from port to starboard heavily until the vessel returned to the seminormal position. At approximately 1305, the captain made an announcement requesting that the Bosun pumped port top side tanks numbers 2,3 , and 4 to correct the list that was reported to be approximately 3 degrees to the starboard side [27].

While lifejackets were being donned, crewmembers left their posts and moved towards the upper decks. As the captain tried to convince crewmembers to return to their respective places of work, the list of the vessel increased to 6 degrees starboard. As the Chief Engineer made his way to the main deck, he saw the vessel's bow deck nearly touching the sea surface and at this time he heard the abandon ship signal [27].

Some of the crew went to port side to try to release the lifeboat but despite the efforts, it could not be released due to the now 20-degree list to the starboard side. The Chief Engineer lost hold of the railing and went into the sea with multiple crewmembers who were either in life rafts or also in the sea [27].

At approximately 1800, a search and rescue helicopter rescued the Chief Engineer and another crewmember while another vessel rescued 12 more. 10 crewmembers are still missing and presumed dead [27].

2.5.2. Investigation Conclusions. The following are the main conclusions from the investigation into the sinking of the Hong Wei [27].

(1) Many mines in the regions where these cargoes are available to carry are very basic and are situated in very remote locations, making it hard for surveyors and experts to attend them. Moreover, it is not easy to arrange for cargo samples to be tested independently due to the lack of reliable laboratories in such countries. 


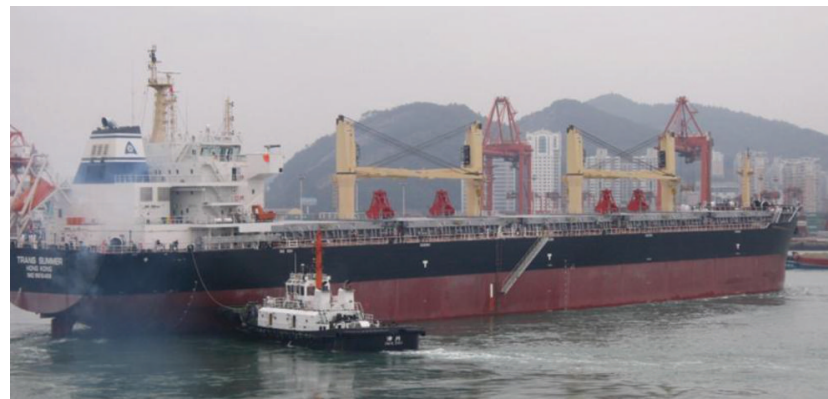

FIgure 18: The Trans Summer [30].

(2) The nickel ore is mined from open quarries and stored in open areas where stockpiles are susceptible to heavy rainfall and high humidity prior to shipment. In some cases, the ore is transported directly from the mine to the vessel.

(3) The "solar drying" of stockpiles has limited effect and rarely does more than dry the surface area of the ore. No other processing is involved. The ore is typically loaded into barges and transhipped to bulk carriers waiting at anchor. Although the cargo presented for shipment may appear to be dry, this is not a guide as to whether the cargo is actually safe to carry.

(4) Nickel ore is nonhomogenous cargo and particle sizes vary considerably. This creates problems for laboratories when trying to ascertain the flow moisture point from which the transport moisture limit is calculated. Local test facilities in these problem areas are not able to complete the testing required by the new IMSBC Code. The required shipping documentation, actual moisture content, and transport moisture limit may therefore be very inaccurate.

(5) The nonhomogenous nature of nickel ore means that cargo loaded in different holds may be inconsistent from one hold to the next with respect to the flow moisture point of cargo in such different holds.

(6) In summary the evidence suggest that the direct cause of this accident was the loss of stability as a result of cargo liquefaction and shift in bad weather.

2.6. Case Study 6: Trans Summer. Built in 2012, the Hong Kong flag Trans Summer (IMO: 9615468) was a handymax bulk carrier with a summer deadweight of 56,824 tonnes [32]. The vessel, which had a length of $190 \mathrm{~m}$, breadth of $31 \mathrm{~m}$, and summer draught of $13 \mathrm{~m}$, had five cargo holds serviced by four on-board cranes [30]. The Trans Summer can be seen in Figure 18.

2.6.1. Summary of Incident. On 15 July 2013, the Trans Summer arrived at Subaim, Indonesia, seen in Figure 19, to begin loading a cargo of nickel ore from shore barges. Prior to arrival, on 10 July, a precaution notice was sent to the Master reminding him to pay particular attention to the possible high moisture content of the nickel ore cargo. Moreover, the "Can

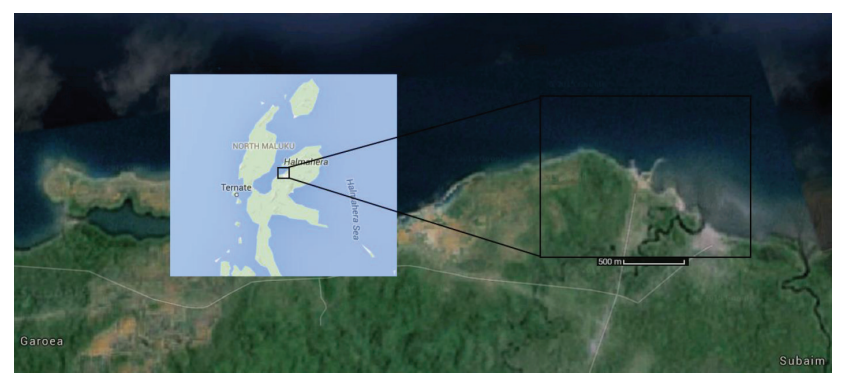

FIgURE 19: Port of Subaim, Indonesia (source: Google Maps).

Test" should be conducted on each barge so as to satisfy himself before loading the cargo on board [30].

Loading commenced on 17 July at 1230 after the Chief Officer and Chief Engineer inspected the nickel ore mine. Although the Master had already received a cargo declaration together with a moisture certificate issued by shipper, the Chief Officer and Chief Engineer did not verify the conditions of cargo stockpiles nor were they aware whether the cargo stockpiles would be covered by tarpaulins to prevent wetting. The cargo declaration showed that the moisture content at time of sampling was $33.87 \%$ and had a flow moisture point of $38.66 \%$ with a resulting transportable moisture limit of $34.79 \%$ [30].

It was noted that it rained frequently during the loading of cargo. To avoid rainwater wetting the cargo, the loading operation was suspended during these times. The crew on board the vessel closed the cargo hold hatches while the stevedores on the barges covered the cargo using tarpaulins [30].

A "Can Test" was performed on each barge prior to transfer to the Trans Summer. The "Can Test" samples were taken from approximately $1 \mathrm{~m}$ below the cargo surface. If the "Can Test" failed, the moisture content was determined and if the moisture content was found to exceed the transportable moisture limit then the cargo was rejected. The results of all the cargo moisture content tests were recorded and sent to the vessels owner [30].

Subsequently, all documents on the vessel including the above records were lost in the accident. The information regarding the cargo loading sequences was retrieved from emails exchanged between the Trans Summer and the vessels owner, as seen in Table 3 [30].

As seen in Table 3, on 23 July a moisture content certificate was received; however, nobody on board the vessel checked the cargo declaration and certificate. As a consequence, they did not know the moisture content of cargo loaded into the cargo holds from 24 to 30 July. On 30 July, the moisture content certificate was checked by the crew and it was sent to the company. It showed that the moisture content at time of sampling was $33.88 \%$ and had a flow moisture point of $38.69 \%$ and a resulting transportable moisture limit of $34.80 \%$. Table 3 revealed that the vessel accepted cargo on two occasions with a moisture content exceeding the transportable moisture limit [30].

The loading was completed on 6 August with the distribution of cargo in the holds shown in Table 4. On 7 August 
TABLE 3: The loading sequence of the Trans Summer [30].

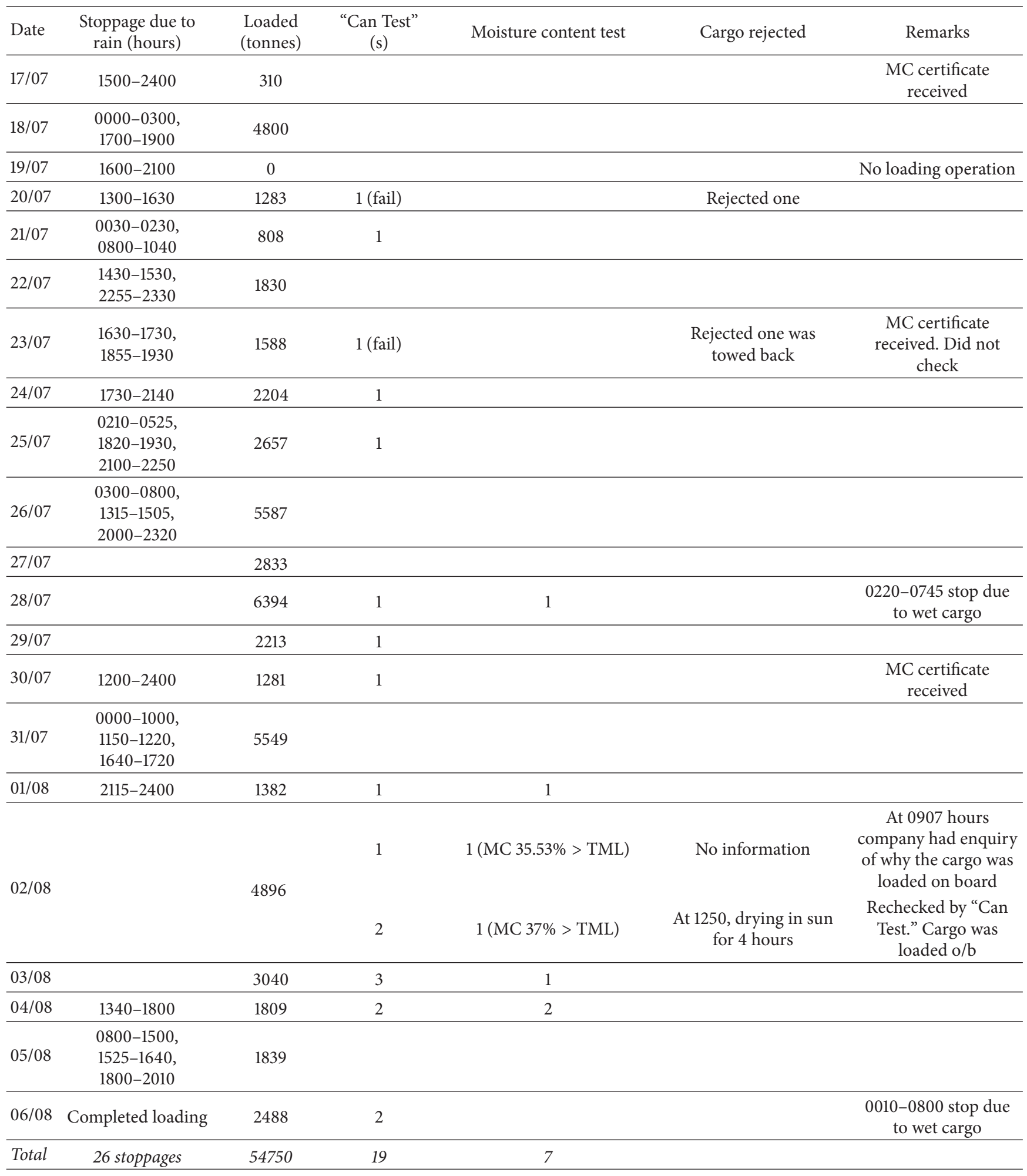

at approximately 1342, the vessel departed Subaim, Indonesia, bound for her discharge port in Yangjiang, China. Everything was found normal upon departure with the stability of the vessel intact [30].
During the voyage, on 9 August, the cargo in hold number 4 was inspected and found to be normal. No further inspections were performed. On the same day, the Master was informed to monitor a tropical depression developing in the 
TABle 4: Cargo distribution of the Trans Summer when departing Subaim, Indonesia [30].

\begin{tabular}{lc}
\hline Cargo hold number & $\begin{array}{c}\text { Quantity of nickel } \\
\text { ore (tonnes) }\end{array}$ \\
\hline 1 & 10,708 \\
2 & 11,602 \\
3 & 9,948 \\
4 & 11,159 \\
5 & 11,333 \\
\hline Total & 54750 \\
\hline
\end{tabular}

Philippines. On 10 August, the tropical depression developed into typhoon "Utor," which was predicted to make landfall close to Trans Summer's discharge port in Yangjiang, China. Typhoon precautionary measures were then executed by the crew [30].

On 12 August at 1540, the Master altered course towards Wanshan QuanDao, China (about 100 miles from Yangjiang), to shelter from the typhoon. On 13 August at 2000, after anchoring 2 nautical miles off the coast, easterly winds increased to force of 8 to 9 and wave height increased to approximately 5 to 6 meters. The rolling and yawing of the vessel at this time were 10 degrees with increasing periods [30].

Early morning on 14 August, the wind was continuing at force 9 blowing in an easterly direction and the vessel was yawing about 10 degrees and rolling about 7 to 8 degrees. At 0757 , the wind was now blowing from the southeast at force 9 with wave heights about 4 to 6 meters. The distance to typhoon centre was about 120 nautical miles. At 1000, the wind force intensified to force 10 with wave heights up to 7 meters. At 1010, a high wave rushed from the starboard side causing the vessel to heel port side more than 20 degrees immersing the deck edge in water. The vessel then rolled back and stayed listing about 10 degrees to port. The listing to port then increased to 15 degrees soon afterwards and persisted [30].

Ballast was then used to try to correct the list but it was mistakenly pumped into the starboard top tanks instead of the double bottom tanks causing the vessels centre of gravity to increase. At 1030, when the vessel listed to port about 17 degrees, the second officer transmitted a distress signal under Master's order and life rafts and the lifeboat were prepared for launching. The Master announced abandon ship at 1105 the same day [30]. The track of "Utor" on 14 August at 1200 can be seen in Figure 20.

As the vessel listed to port more than 22 degrees, the Master ordered all crewmembers to jump into the sea from the stern deck and board the inflated life rafts. As rescue operations commenced, the vessel listed to port more than 90 degrees and subsequently sank on 14 August at 1156. Views from a rescue helicopter can be seen in Figures 21 and 22. The vessel had dredged the anchor more than half a nautical mile north-west from its original position.

Fortunately, helicopters and vessels sent to the location of the Trans Summer rescued all crewmembers, but the deck log along with other statutory documents was lost at sea [30].
2.6.2. Investigation Conclusions. The following are the main conclusions from the investigation into the sinking of the Trans Summer [30].

(1) The requirements of IMSBC Code for the cargo of nickel ore, under groups A and B, were not strictly followed. The cargo was loaded despite the moisture content, which exceeded the transportable moisture limit of $34.8 \%$.

(2) The safety shipboard procedures for loading and carriage of nickel ore were not followed. The relevant procedures were as follows:

(a) The procedure for handling of cargo.

(b) The instruction of handling of bulk cargo which may liquefy.

(c) The requirement of cargo care at sea.

(d) The instruction for preventing strong wind.

(e) The voyage instruction.

(3) Liquefaction of cargo inside cargo holds while the anchored vessel experienced rolling at the anchorage, compounded by worsening weather and sea condition due to approaching of typhoon and mistakenly pumping water into ballast tank.

(4) Master's assessment to select the shelter for the vessel to anchor was not appropriate. The place selected by the Master could shelter the wind from the north only. The vessel could not shelter from the south-easterly strong wind and waves when the typhoon "Utor" was passing the south of the vessel.

(5) The moisture content certificate was issued by the shipper instead of local administration or independent organization (or authorized organization).

(6) The crew was not trained and therefore not competent to carry out Oven Drying Testing on board to verify the moisture content of the cargo before loading.

2.7. Case Study 7: Bulk Jupiter. Built in 2006, the Bahama flag Bulk Jupiter (IMO: 9339947) was a handymax bulk carrier with a summer deadweight of 56,009 tonnes [32]. The vessel, which had a length of $190 \mathrm{~m}$, breadth of $32 \mathrm{~m}$, and draught of $13 \mathrm{~m}$, had five cargo holds serviced by four on-board cranes [28]. The Bulk Jupiter can be seen in Figure 23.

2.7.1. Summary of Incident. On 12 December 2014, the Bulk Jupiter arrived at the Port of Kuantan, Malaysia, seen in Figure 24, to begin loading a cargo of bauxite from a berth. The cargo loading operations were delayed due to heavy and prolonged rainfall until 17 December at 2100, at which point loading of holds numbers $1,3,4$, and 5 commenced. Loading of hold number 2 commenced on 18 December [28].

The east coast of Malaysia had endured record-breaking rainfall over the month of December, recording the highest monthly rainfall in the history of Kuantan at $1806.4 \mathrm{~mm}$ over a 22-day period, as seen in Figure 25. The loading operations continued for an extended period of time due to heavy rain 


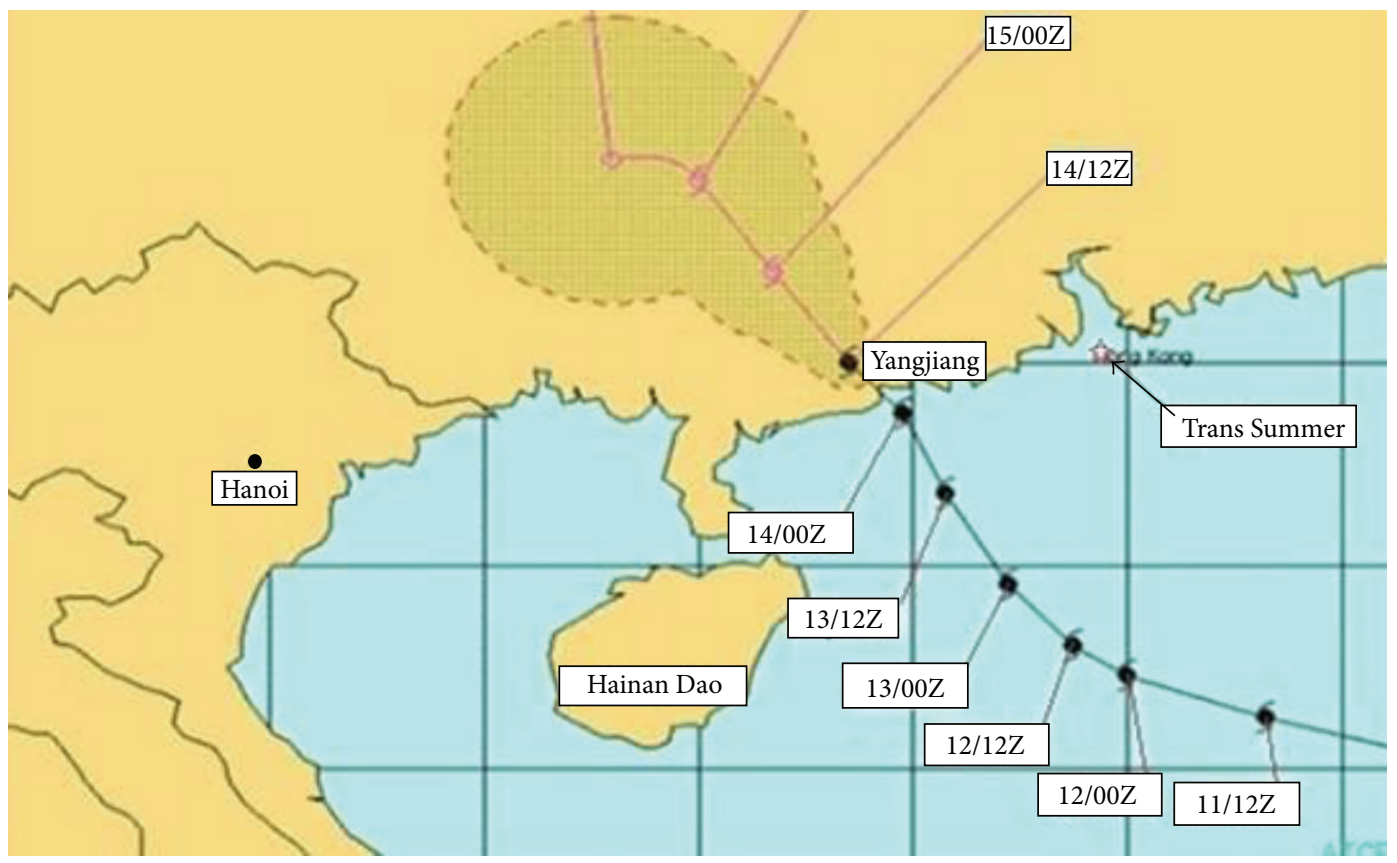

Figure 20: Track of "Utor" on 14 August at 1200 (predicted track in red) [30].

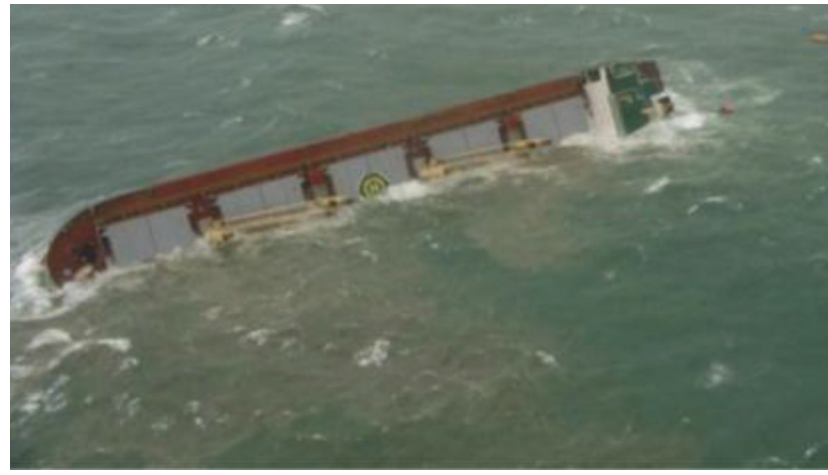

FIgURE 21: View from rescue helicopter as the Trans Summer listed 45 degrees to port [30].

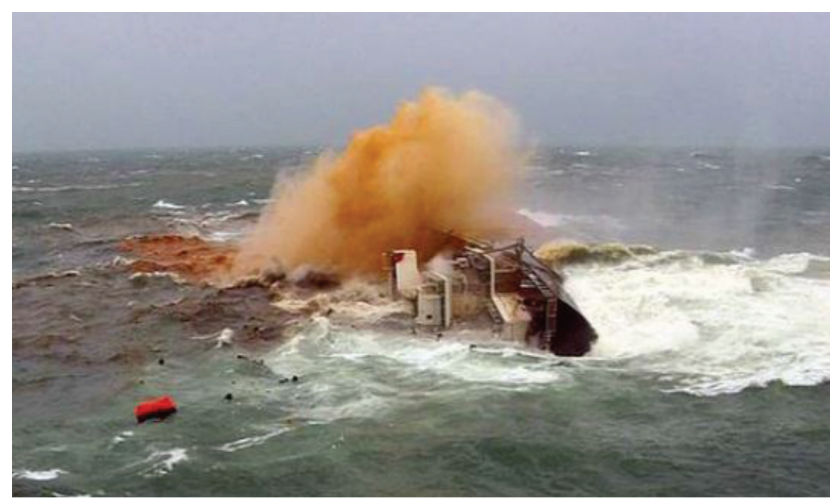

FIGURE 22: View from rescue helicopter as the Trans Summer listed 90 degrees to port [30].

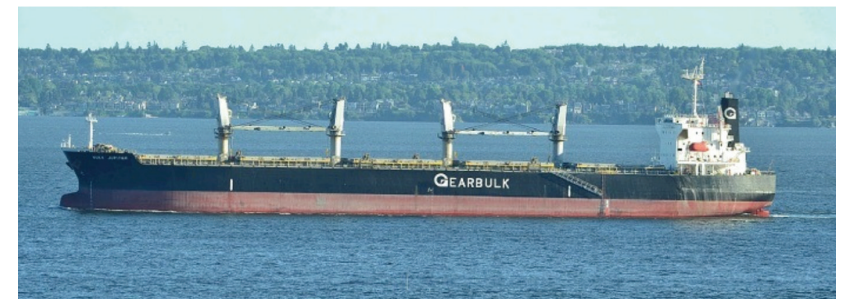

Figure 23: The Bulk Jupiter [28].

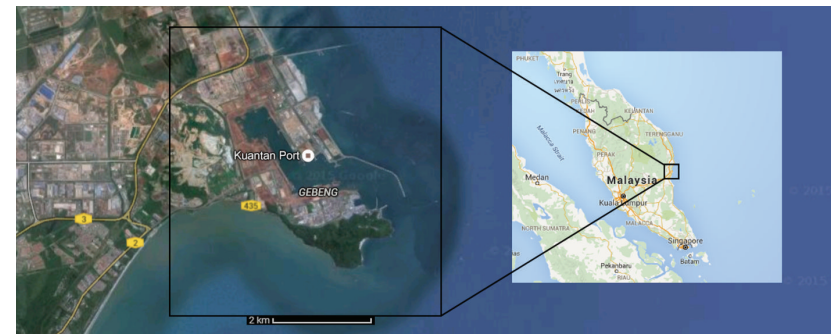

Figure 24: Port of Kuantan, Malaysia (source: Google Maps).

and technical delays. During periods of rain, vessels generally close their hatch covers to prevent any moisture from entering cargo holds and maintain the cargo in a dry condition. However, any cargo left on the quayside is left uncovered and therefore exposed to the elements. It is very likely that the moisture content of the bauxite increased during this time [28].

Loading of Bauxite onto bulk carriers at the Port of Kuantan is achieved using the on-board cranes, as seen in 


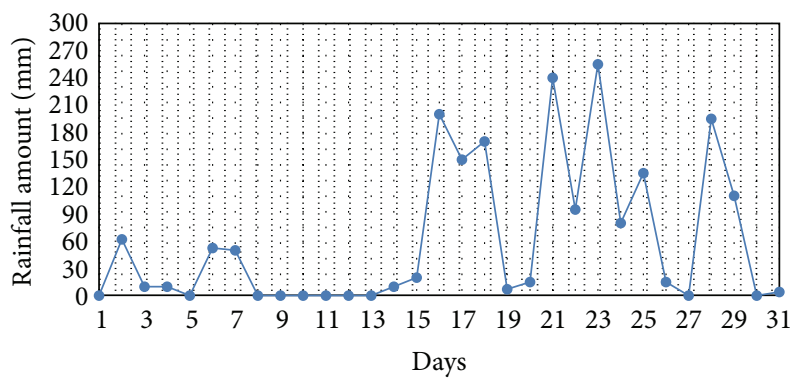

Figure 25: December rainfall at the Port of Kuantan, Malaysia [28].

Figure 26. The bauxite is transported to the port on load trucks where they either store the cargo in stockpiles or storage facilities or transport the bauxite directly to the quayside. Noted in the investigation was that during transport and storage the bauxite is generally not covered to protect it from rain [28].

There are a number of mines dotted around the Port of Kuantan with varying sizes of operations. It was also noted that there was also no covered storage facility at these mines which affords any protection from the rain or surface water runoff [28]. At the time of loading there was no transportable moisture limit test performed on the bauxite as in the IMSBC Code, under the individual schedule for bauxite, it did not state the cargo was potentially liquefiable [19].

On 30 December at 2124, the Bulk Jupiter left Kuantan, Malaysia, bound for Qingdao, China, with 46,400 tonnes of bauxite on board and stability intact. After clearing the breakwater, the vessel was observed to be rolling about 2 to 3 degrees in low swell. The pilot did not note any abnormal behaviour in the way the vessel handled while she was being pulled off the berth or while being manoeuvred through the port and channel [28].

On 31 December, part way into the voyage, the weather deteriorated. Wind was forecast north-east at a force of 6 to 7, wind speed 24 to 34 knots, and sea state from 4 to 6 and with an average wave height of $2.2 \mathrm{~m}$. On 1 January, the Master received a weather forecast that included alternate waypoints for the vessel to travel to reduce the exposure to gale force winds and waves between 2.5 to $4 \mathrm{~m}$ from a tropical storm in the north east [28]. The route of the Bulk Jupiter and location the bulk carrier lost can be seen in Figure 27.

On 2 January 2015 at approximately 0600, the Chief Cook awoke and noted the weather was starting to deteriorate and the vessel was rolling more heavily than the previous day. At approximately 0640 , the general alarm was sounded followed by an announcement by the Master directing all crew to proceed to the bridge. The Chief Cook made his way to the bridge but was told by fellow crewmembers to instead proceed to the port side lifeboat [28].

At 0654 , a distress signal was sent out by the Bulk Jupiter, which initiated search and rescue operations. As the Chief Cook returned to his cabin to collect some belongings, he felt the vessel suddenly start to roll more heavily, particularly to starboard. As he left his cabin, the vessel suffered a blackout and emergency lights illuminated. The vessel then stopped rolling and adopted a 45-degree list to the starboard side. After meeting the Master, they both abandoned the vessel on the starboard side [28].

The Bulk Jupiter was founded southeast of Vietnam between the time of the distress signal and 0700 . As the search for survivors continued throughout the day, at 1556, the Chief Cook was recovered. Search and rescue operations ceased on the 06 January. The Chief Cook was the only survivor of the 19 crewmembers on board [28].

Bauxite cargo in the hold of another bulk carrier, the Orchid Island, which left the Port of Kuantan on 1 January 2015, shortly after the Bulk Jupiter, can be seen in Figure 28. This cargo of bauxite was suspected to have liquefied during the voyage. Note the extensive "splatter" on the sides of the cargo hold. An additional photo, seen in Figure 29, taken from the Medi Okinawa shows bauxite on the quayside open to the elements. The Medi Okinawa arrived at Kuantan shortly before the Bulk Jupiter but sailed on 21 January 2015, after discharging the cargo of bauxite that was loaded because the cargo failed to meet the description contained in the declaration provided [28].

2.7.2. Investigation Conclusions. The following are the main conclusions from the investigation into the sinking of the Bulk Jupiter [28].

(1) There is significant documentary evidence to identify that the $46,400 \mathrm{t}$ of bauxite loaded over the course of the 13-day period had an average moisture content of $21.3 \%$. Despite this, there is no physical evidence to confirm what caused the vessel to adopt an unrecoverable list to starboard and subsequent capsize.

(2) It was found that the cargo declarations were considered generic, including the declared $10 \%$ moisture content of the cargo. This was found when comparisons were made between the Bulk Jupiter's cargo declaration and declarations of the bulk carriers Orchid Island and Medi Okinawa.

(3) Communications between the Master and the company ship manager indicated the Master had a lack of understanding of the practical method for determining excessive moisture content of a bulk cargo, specifically the "Can Test."

(4) In total 186.55 hours of loading was lost due to rainfall, the equivalent of 7 days of loading over the period. The infrastructure available to adequately store and transport bauxite in Kuantan increased the exposure of the bauxite to the elements. Despite the crew's diligent response to the rain by continually opening and closing the hatch covers to reduce the ingress of water, the cargo remained exposed while on the quayside, in stockpiles, and in the trucks.

(5) An independent inspection was not requested by the Master to verify the properties of the cargo prior to loading on board. Considering the extreme weather conditions and storage facilities available it was acknowledged that the cargo was very wet and that 

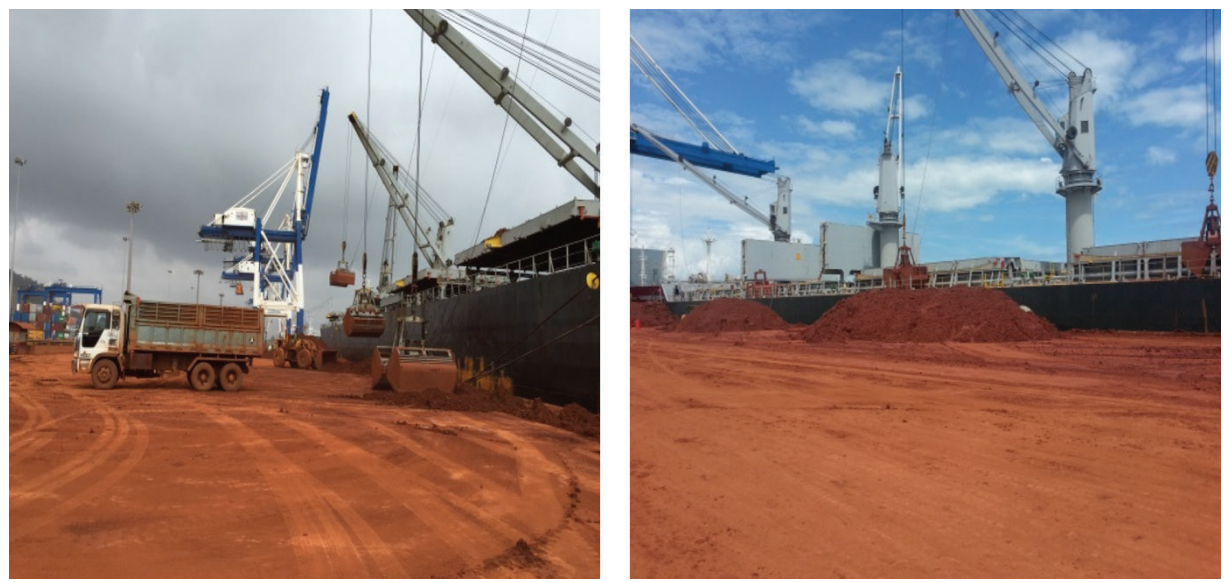

FIgURE 26: Cargo being loaded onto a bulk carrier from the quayside at the Port of Kuantan, Malaysia [28].

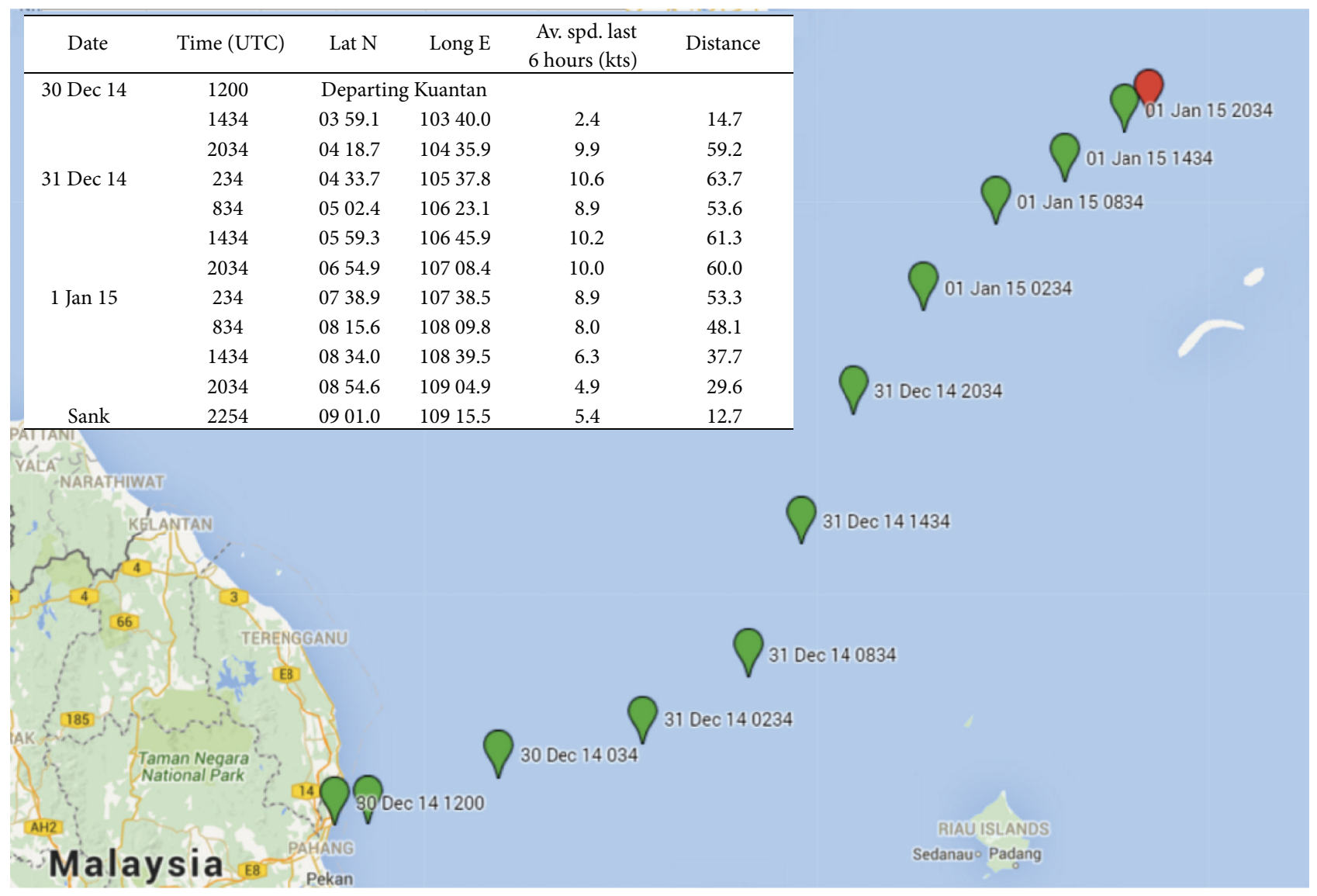

FIGURE 27: Route of the Bulk Jupiter and location lost [28] (source: Google Maps).

measures to protect the cargo on shore from further rain were not effective in preventing further wetting. The absence of an independent inspection resulted in the cargo being loaded without its physical properties and moisture content being verified against the parameters of the IMSBC Code schedule or the cargo declaration form.
(6) Every 48 hours a report should be generated and provided to the Charterers if any water had been drained from the bilges during the transit in accordance with the Charterers Voyage Instructions. No correspondence has been received from the Charterers and therefore it cannot be determined whether the cargo was draining free water and/or whether anyone on 

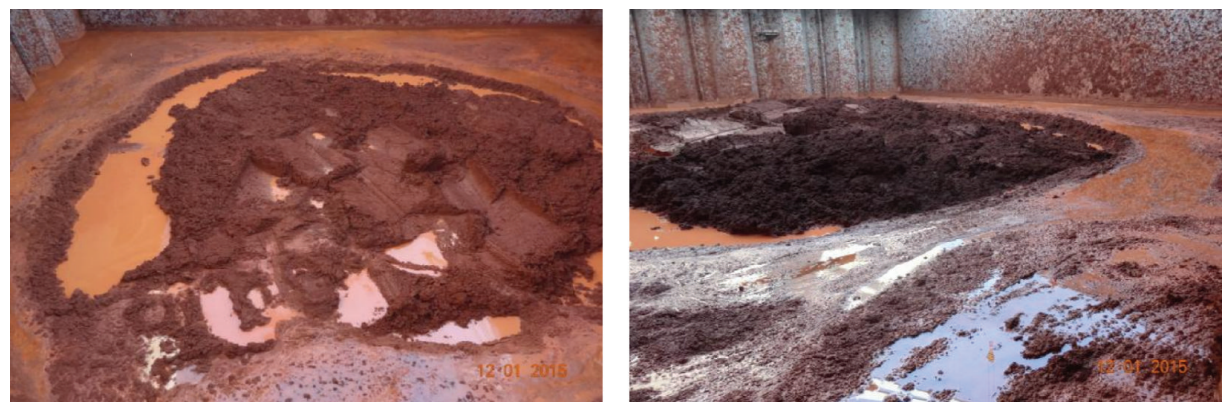

FIGURE 28: View of bauxite cargo in hold number 4 of the Orchid Island after voyage from Kuantan, Malaysia, to Qingdao, China [28].

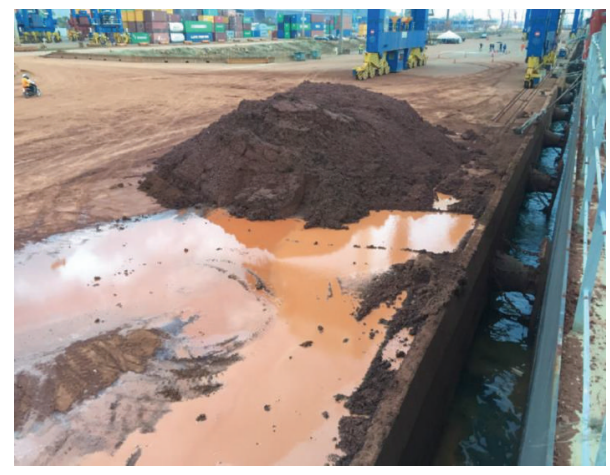

Figure 29: Bauxite cargo quayside exposed to the elements. Photo taken from the Medi Okinawa at Port of Kuantan, Malaysia [28].

board was aware and was taking action to discharge any water accumulating in the hold bilges.

(7) The previous class and special survey inspections indicate no structural integrity failures; the vessel had fulfilled diligently all prior certification conformity requirements and as such the likelihood of a catastrophic structural failure is considered low.

(8) Having presumed that the probability of structural failure is low, as a singular causal event, it can be concluded that either liquefaction or a free surface effect induced an unrecoverable list. When considering the conditions in the order that they occurred, there can only be very few circumstances that cause a vessel to capsize so quickly with minimal warning. Due to the reliability of the information provided on the cargo declaration, in particular the composition of cargo, it has been determined that the probability of liquefaction occurring is considered high. A further causal event, for which it would only occur if the cargo is sufficiently compacted, is a free surface effect generated on top of the cargo. Notwithstanding this, if the cargo had liquefied, a free surface effect will also occur, with similar catastrophic effect. Another related phenomenon associated with both liquefaction and free surface effect occurs when the cargo slides to one side of the vessel and fails to return to where it came from. This particular effect would be inevitable once the angle of heel is greater than the angle of repose of the cargo, if untrimmed or if the cohesion between the particles of the cargo is insufficient when an angle of heel is induced.

\section{Discussion and Recommendations}

As discussed in Section 1, there are many factors that influence the liquefaction potential of cargoes. Although this is the case, the moisture content is one that can change significantly during extraction, storage, and transportation. It can change significantly based on the implemented procedures and the actions of the people involved in these processes. Despite the fact that some reports indicate that excess moisture within the cargo is only assumed to have been the cause of the incident, we will assume that in all cases excess moisture within the cargo was the cause of the incident.

Determining if a cargo is safe to transport is relatively simple if the correct sampling and testing techniques are implemented. The importance of sampling is commonly overlooked but is the most imperative aspect of any laboratory testing [38]. If the sample does not represent the cargo being transported then the results will be misleading. There are many techniques for sampling stockpiles depending on the type of material and standards being followed (i.e., iron ore [39]). Section 4.6 of the IMSBC Code outlines sampling procedures that are to be followed when sampling stockpiles consigned to vessels [19]. It is recommended these sampling techniques be used when determining the moisture content and transportable moisture limit of a cargo.

Once a representative sample of the cargo has been obtained, prior to the arrival of a vessel, it is recommended to determine both the average moisture content and transportable moisture limit of the stockpile. For bauxite and nickel ore, there are no test methods specifically designed to determine the transportable moisture limit. Until such a test is developed, it is recommended to utilize either the penetration test or flow table test stated in Appendix 2 of the IMSBC Code [19]. These tests are recommended as they measure the direct liquefaction potential with visual observations [11, 21]. Like iron ore fines and coal, it is recommended that a test be developed that is specifically designed for determining the transportable moisture limit of bauxite and nickel ore and the IMSBC Code specify mandatory testing of all variations of these cargoes [40-44]. 
From the reports, it is clear that the ingress of water into the cargo is a major problem during transportation, storage, and loading, prior to a vessels departure from port. It is commonly reported that trucks and barges are not equipped with tarpaulins to protect the cargo from rain. Additionally, stockpiles at the mines and quayside also lack this essential equipment. Cargoes such as nickel ore and bauxite can contain a significant amount of fine particles $[45,46]$. This property can also increase the cargoes' hygroscopic properties [47]. Protective equipment should be easily accessible and readily available for use when rain is forecast. Masters should insist on checking if this protective equipment is available, as if this equipment is unavailable it can be an indication of poor practices at the site and therefore the Master should be extra vigilant.

"Solar drying" of stockpiles of cargo is an ineffective method for rapidly reducing the moisture content. The method merely dries the surface of the stockpile leaving the core of the stockpile unaffected $[48,49]$. If "solar drying" is to be carried out, it is recommended that the cargo be evenly spread on a pad and frequently turned over using a bulldozer or excavator to increase the rate of evaporation and distribution of desiccation. Drying or dewatering a cargo can take some time to accomplish; therefore, prior to arrival of a vessel, it is recommended that the moisture content of the cargo is determined and compared with the transportable moisture limit in order to decide if drying is needed.

Moisture content testing is inexpensive when compared to the cost that will be incurred if a vessel is lost due to a cargo liquefying or shifting. After the arrival of a vessel, prior to loading, the exact moisture content of the cargo should be known. Section 4.5 of the IMSBC Code states that the interval between moisture content sampling should not be more than seven days prior to loading [19]. This statement can be misleading as the moisture content of a cargo can change significantly within seven days. If rainfall has occurred during this time or the air humidity has been high, it is highly recommended that a few hours prior to loading additional moisture content tests be performed for confirmation.

It is recommended that an accredited independent testing laboratory is available to perform the required moisture content and transportable moisture limit testing. These laboratories may be located at the mine or port and be under the supervision of the International Maritime Organization and funded by the export company. After testing, if the Master suspects that a cargo may contain a moisture content that exceeds the transportable moisture limit then it is recommended that a "Can Test" is also performed on the cargo.

The "Can Test" is an in situ complementary test procedure for determining the liquefaction potential of a cargo given in the IMSBC Code [19]. The "Can Test" provides an estimate on whether the cargo may exceed the transportable moisture limit. Masters should be familiar with the "Can Test" and moisture content test if they are frequently transporting potentially liquefiable cargoes. The "Can Test" is usually the last line of defense for preventing cargoes exceeding the transportable moisture limit being loaded onto a bulk carrier. Failure of this test indicates the cargo is not safe to transport and should be rejected unless it is proven that the cargo has a moisture content less than the transportable moisture limit. Even then, extra precautions should be taken and the validity of the transportable moisture limit test should be questioned.

Once a cargo is loaded onto a bulk carrier, it is still susceptible to the ingress of moisture. During loading, it is highly recommended that when rain is forecast all cargo holds be closed. The ingress of water into the holds can sometimes be removed by bilge pumps, but due to some cargoes ability to retain moisture it can be preserved within and migrate out during transportation.

During transportation, dynamic loading, caused by the ocean waves and vessel vibrations, can cause a cargo to densify. Dynamic loading can reduce the voids of a cargo and in turn this increases the degree of saturation and induces changes in the pore pressures within the material. A cargo that is highly saturated may be at risk of liquefying and shifting within the hold of a bulk carrier [50]. In Appendix 1 of the IMSBC Code, it is recommended that cargoes be checked regularly to make sure that there are no changes in the state of the material. The IMSBC Code states "The appearance of the surface of the cargo shall be checked regularly during a voyage. If free water above the cargo or fluid state of the cargo is observed during a voyage, the Master shall take appropriate actions to prevent cargo shifting and potential capsize of the ship, and give consideration to seeking emergency entry into a place of refuge" [19].

As the degree of saturation of a cargo increases, so does the degree to which it can densify. Densification may cause excess moisture to migrate to the surface. It has been proven that this process occurs gradually with the speed related to the magnitude and time of dynamic loading. It is recommended that regular check on the cargo be made, with frequently increasing checks being performed if the vessel experiences rough sea states.

\section{Conclusion}

The objective of this study was to investigate the collective causes of liquefaction of solid bulk cargoes on board bulk carriers in order to make recommendations to prevent future incidents from occurring. This was achieved by analysing the available investigative reports relating to the incidents, focusing on the key findings and exploring the effect of excess moisture within the cargo. This study placed significant emphasis on the importance of preventing ingress of water into the cargo during transportation, loading, and storage.

Although the International Maritime Solid Bulk Cargoes Code (IMSBC Code) was implemented on a mandatory basis from January 2011, incidents involving liquefaction of mineral bulk cargoes continue to occur.

The findings of this study indicate that liquefaction incidents on board bulk carriers are caused by a combination of below par procedural implementation along with insufficient knowledge about liquefaction of cargoes and the possible consequences of transporting them with a high moisture content. Sampling and testing techniques that may not be mandatory are necessary in order to reduce liquefaction incidents from occurring. 
Many mines where bauxite and nickel ore are being extracted are very basic and situated in remote locations. This makes it hard for surveyors and experts to attend them. Hence, it is not easy to arrange for cargo samples to be tested independently due to the lack of reliable laboratories in these remote areas. Due to this, the responsibly falls back onto the individual mine operators, the port authority, and the Master of the vessel to make sure that the test results are valid and representative of the cargo as well as that all necessary precautions are taken to reduce the potential for the cargo to liquefy.

Although it is not mandatory to determine the transportable moisture limit of certain bauxite and nickel ore cargoes, it is highly recommended to do so as incidents are continuing to occur when transporting these cargoes on bulk carriers. Additionally, although a cargo may appear dry, it could contain excessive moisture and become saturated under dynamic loading. It is essential that the moisture content of a cargo is kept low to reduce the risk of liquefaction or cargo shift and that further research is performed to determine the physical properties and system variables that increase the liquefaction potential of these cargoes.

\section{Abbreviations}

FMP: $\quad$ Flow moisture point

IMO: International Maritime Organization

IMSBC Code: International Maritime Solid Bulk Cargoes Code (formally the Code of Safe Practice for Solid Bulk Cargoes (BC Code))

TML: $\quad$ Transportable moisture limit.

\section{Competing Interests}

The authors declare that they have no competing interests.

\section{Acknowledgments}

The results presented in this publication are from an ongoing study at RMIT University in Melbourne, Australia, on the liquefaction potential of mineral cargoes on board bulk carriers.

\section{References}

[1] L. A. van Paassen, P. J. Vardon, A. Mulder, G. van de Weg, and P. Jeffrey, "Investigating the susceptibility of iron ore to liquefaction," in Proceedings of the Fifth Biot Conference on Poromechanics (Poromechanics V '13), pp. 1478-1487, Vienna, Austria, July 2013.

[2] Y. Zou, C. Shen, and X. Xi, "Numerical simulations on the capsizing of bulk carriers with nickel ores," Journal of Navigation, vol. 66, no. 6, pp. 919-930, 2013.

[3] D. Cabai, "Dealing with dry cargo liquefaction," Naval Architect, pp. 16-18, 2011.

[4] K. Ishihara, "Stability of natural deposits during Earthquakes," in Proceedings of the 11th International Conference on Soil Mechanics and Foundation Engineering, pp. 321-376, San Francisco, Calif, USA, 1985.
[5] K. Ishihara, "Liquefaction and flow failure during earthquakes," Geotechnique, vol. 43, no. 3, pp. 351-415, 1993.

[6] H. B. Seed and I. M. Idriss, "Simplified procedure for evaluating soil liquefaction potential," Journal of the Soil Mechanics and Foundations Division, vol. 97, no. 9, pp. 1249-1273, 1971.

[7] H. B. Seed and I. M. Idriss, Ground Motions and Soil Liquefaction during Earthquakes, Monograph Series, Earthquake Engineering Research Institute, 1982.

[8] B. Fagerberg and A. Stavang, "Determination of critical moisture contents in ore concentrates carried in cargo vessels," Minerals Transportation, pp. 174-191, 1971.

[9] M. M. Rahman, M. A. L. Baki, and S. R. Lo, "Prediction of undrained monotonic and cyclic liquefaction behavior of sand with fines based on the equivalent granular state parameter," International Journal of Geomechanics, vol. 14, no. 2, pp. 254266, 2014.

[10] M. Rahman and S. R. Lo, "Predicting the onset of static liquefaction of loose sand with fines," Journal of Geotechnical and Geoenvironmental Engineering, vol. 138, no. 8, pp.1037-1041, 2012.

[11] M. C. Munro and A. Mohajerani, "Determination of the transportable moisture limit of iron ore fines for the prevention of liquefaction in bulk carriers," Marine Structures, vol. 40, no. 1, pp. 193-224, 2015.

[12] C. Andrei and R. H. Pazara, "The impact of bulk cargoes liquefaction on ship's intact stability," UPB Scientific Bulletin, vol. 75, no. 4, pp. 47-58, 2013.

[13] K. Terzaghi, R. Peck, and G. Mesri, Soil Mechanics in Engineering Practice, John Wiley \& Sons, New York, NY, USA, 3rd edition, 1996.

[14] G. R. Martin, H. B. Seed, and W. D. L. Finn, "Fundamentals of liquefaction under cyclic loading," Journal of the Geotechnical Engineering Division, vol. 101, no. 5, pp. 423-438, 1975.

[15] J. A. Sladen, R. D. D'Hollander, and J. Krahn, “The liquefaction of sands, a collapse surface approach," Canadian Geotechnical Journal, vol. 22, no. 4, pp. 564-578, 1985.

[16] A. L. Baki, M. Rahman, and S. R. Lo, "Cyclic instability behaviour of coal ash," in Proceedings of the GeoCongress 2012, GSP 225, pp. 849-858, Oakland, Calif, USA, March 2012.

[17] R. Mohamad and R. Dobry, "Undrained monotonic and cyclic triaxial strength of sand," Journal of Geotechnical Engineering, vol. 112, no. 10, pp. 941-958, 1986.

[18] P. Grunau, Cargo Handling and Stowage: A Guide for Loading, Handling, Stowage, Securing and Transportation of Different Types of Cargoes, Except Liquid Cargoes and Gas, 2012.

[19] International Maritime Organization, International Maritime Solid Bulk Cargoes Code, International Maritime Organization, London, UK, 2013.

[20] International Maritime Organization, Adoption of the International Maritime Solid Bulk Cargoes (IMSBC) Code-Resolution MSC.268(85), IMO, London, UK, 2008.

[21] M. Munro and A. Mohajerani, "Moisture content limit of iron ore fines for the prevention of liquefaction in bulk carriers," in Proceedings of the 11th International Conference on Hydrodynamics (ICHD '14), Singapore, October 2014.

[22] M. C. Munro and A. Mohajerani, "Moisture content limits of Iron Ore Fines to prevent liquefaction during transport: review and experimental study," International Journal of Mineral Processing, vol. 148, pp. 137-146, 2016.

[23] Panama Maritime Authority-Maritime Accident Investigation Department, Report: M/V “Jian Fu Star" R-011-11-DIAM, 2011. 
[24] Met Office, National Meteorological Library Archive Fact Sheet 6-The Beaufort Scale (Version 01), Met Office, 2010.

[25] Australian Transport Safety Bureau (ATSB), Marine Safety Investigation (Report 148)-Investigation into the Shift of Cargo on Board the Singapore Flag Bulk Carrier Padang Hawk, Australian Transport Safety Bureau, 2000.

[26] Panama Maritime Authority-Maritime Accident Investigation Department, "Nasco diamond," Report: M/V R-020-2011/ DIAM, 2011.

[27] Panama Maritime Authority-Maritime Accident Investigation Department, Report: M/V "Hong Wei" R-007-2011-DIAM, 2011.

[28] The Bahamas Maritime Authority, "M.V Bulk Jupiter"-Report of the Marine Safety Investigation into the Loss of a Bulk Carrier in the South China Sea on January 2nd 2015, 2015.

[29] The Hong Kong Special Administrative Region-Marine Department-Marine Accident Investigation Section, Report of Investigation into the Sinking of M.V. Hui Long on 20 May 2005-Preliminary Imquiry No. 2 of 2005, 2005.

[30] The Hong Kong Special Administrative Region-Marine Department-Marine Accident Investigation Section, Report of Investigation into Sinking of Hong Kong Registered Bulk Carrier "Trans Summer" at Position $21^{\circ} 55.3^{\prime} \mathrm{N}, 113^{\circ} 40.4^{\prime} \mathrm{E}$ West of Dawanshan Dao, Mainland China on 14 August 2013, 2015.

[31] International Maritime Organization, IMO Identification Number Schemes, 2015, http://www.imo.org/en/OurWork/MSAS/ Pages/IMO-identification-number-scheme.aspx.

[32] UNCTAD Secretariat, "Review of maritime transport," in United Nations Conference on Trade and Development, United Nations, Geneva, Switzerland, 2014.

[33] MarineTraffic, Bulk Carrier-Tong Ji Men, 2015, http://www .marinetraffic.com/pl/ais/details/ships/shipid:407433/mmsi: 351305000/imo:9109354/vessel:CHC\%20NO.3.

[34] MarineTraffic, Bulk Carrier-Jian Fu Star, 2015, http://www .marinetraffic.com/ais/details/ships/shipid:9845/mmsi:-8106379/ imo:8106379/vessel:JIAN_FU_STAR.

[35] Sea Breezes, "Bulk Carrier Losses," 2010, http://www.seabreezes .co.im/index.php?option $=$ com_content $\&$ id $=467$ :bulk-carrierlosses\&Itemid $=50$.

[36] MarineTraffic, Hong Wei-Bulk Carrier, 2015, http://www.marinetraffic.com/ais/details/ships/shipid:6708/mmsi:-9230139/imo: 9230139/vessel:HONG_WEI.

[37] ShipSpotting, DARYA DHYAN-IMO 9230139, 2006, http:// www.shipspotting.com/gallery/photo.php?lid=214774.

[38] A. S. Gard, Loss Prevention Circular No. 01-12-Liquid Bulk Cargo Sampling-Collecting Evidence, 2012.

[39] International Standards Organization, ISO 3087-Iron OresDetermination of Moisture Content of a Lot, 1998.

[40] Australian Coal Association Research Program (ACARP), TML0036-Coal Transportable Moisture Limit Project-Technical Submission to the Australian Maritime Safety Authority (AMSA), 2014.

[41] Australian Coal Association Research Program (ACARP), TML0037-Modified Proctor/Fagerberg Method for Coal, Australian Coal Association Research Program (ACARP), Brisbane, Australia, 2014.

[42] International Maritime Organization, "Amendment 02-13 to the IMSBC Code and Supplements: Inadequacy of current IMSBC code methodologies to transportable moisture limit determination on Brazilian iron ore fines, 17th session, Agenda Item 4, DSC 17/INF.10," in Sub-Committee on Dangerous Goods, Solid Cargoes and Containers, 2012.
[43] International Maritime Organization, Early Implementation of Draft Amendments to the IMSBC Code Related to the Carriage and Testing of Iron Ore Fines (DSC.1/Circ.71), London, UK, 2013.

[44] International Maritime Organization, MSC 95/3/Add.1Amendments to the International Maritime Solid Bulk Cargoes Code (IMSBC Code), London, UK, 2015.

[45] Gard AS, Liquefaction of Solid Bulk Cargoes-A Selection of Articles Previously Published by Gard AS, 2014.

[46] UK P\&I Club, Bauxite Loadings, 2015, http://www.ukpandi.com/ knowledge/article/bauxite-loadings-131638/.

[47] H. Xinwei, C. Hao, L. Xiangquan, C. Xiaomei, L. Lingxia, and W. Zhenxing, "The influence of soil particle on soil condensation water," Advance Journal of Food Science and Technology, vol. 5, no. 6, pp. 712-720, 2013.

[48] The American Club, Dangers with Respect to the Carriage of Nickel Ore and Other Bulk Cargoes Prone to Liquefaction, 2010.

[49] Britannia-The Britannia Steam Ship Insurance Association Limited, "Carriage of nickel ore from the Philippines," Bulletin, July 2015, http://www.britanniapandi.com/assets/Uploads/documents/Carriage-of-nickel-ore-from-the-Philippines-07-2.pdf.

[50] I. A. Koromila, C. C. Spandonidis, and K. J. Spyrou, "Experimental investigation of cargo liquefaction and impact on the stability of a bulk-carrier," in Proceedings of the 13th International Ship Stability Workshop, Brittany, France, September 2013. 

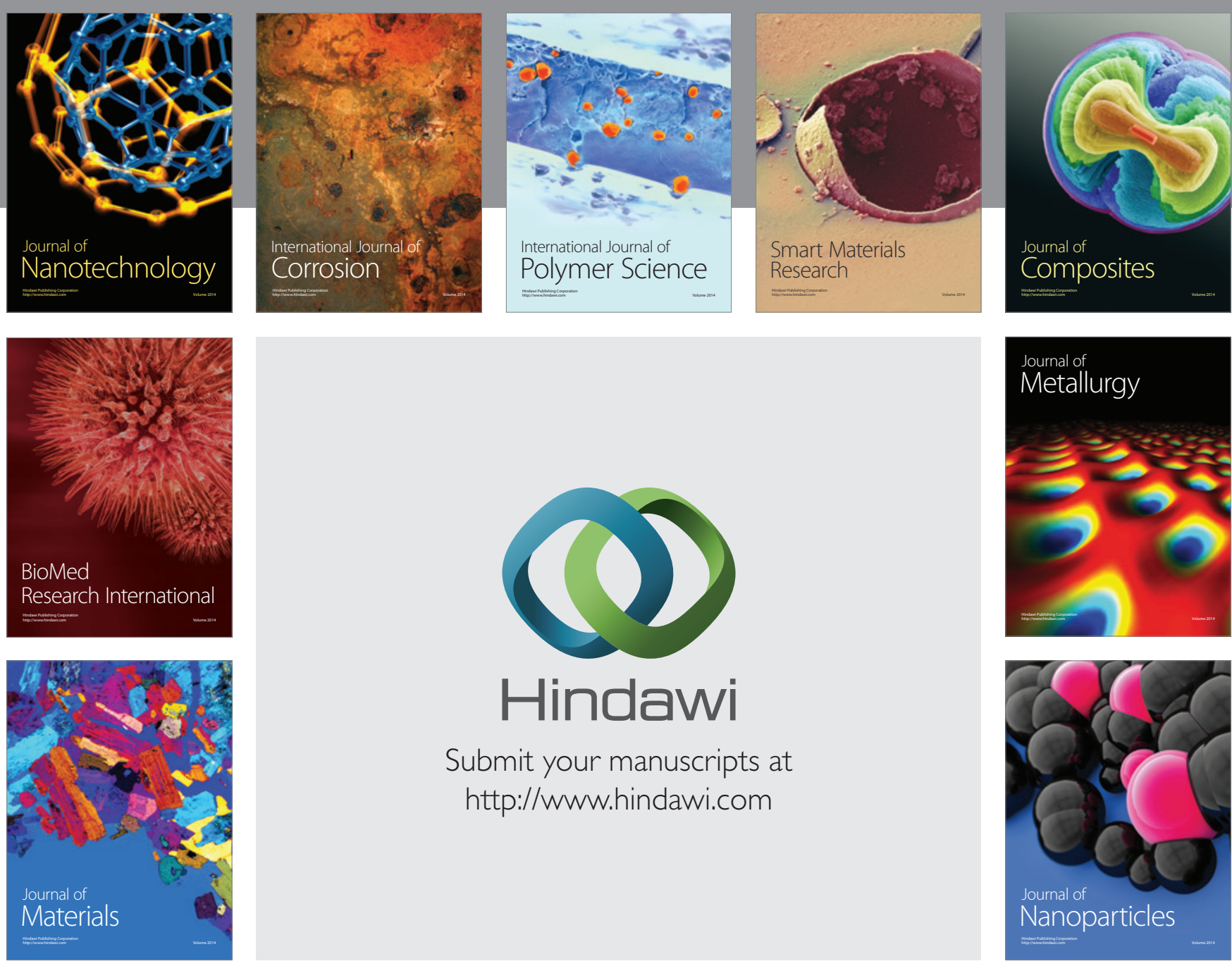

\section{Hindawi}

Submit your manuscripts at

http://www.hindawi.com

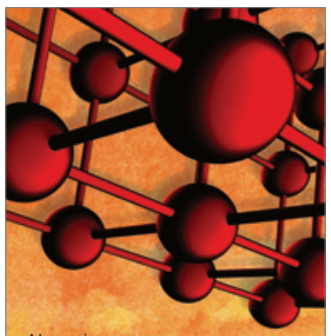

Materials Science and Engineering
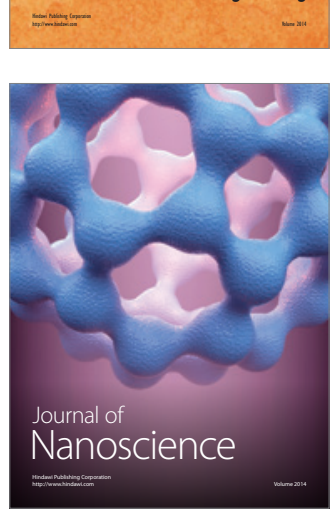
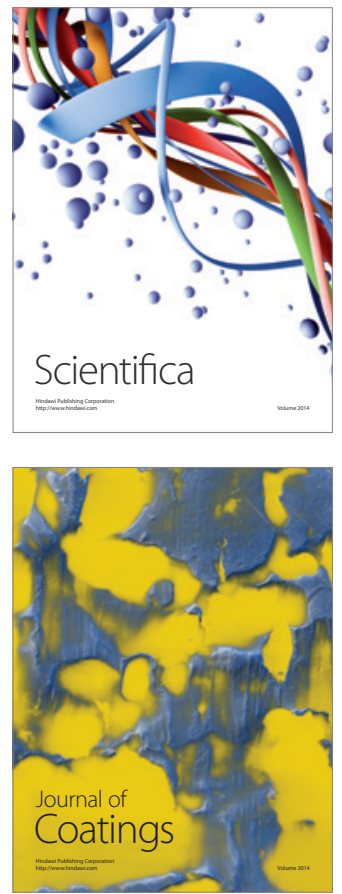
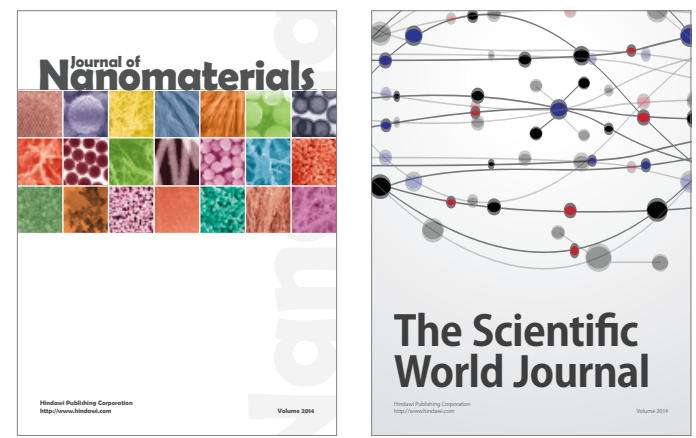

The Scientific World Journal
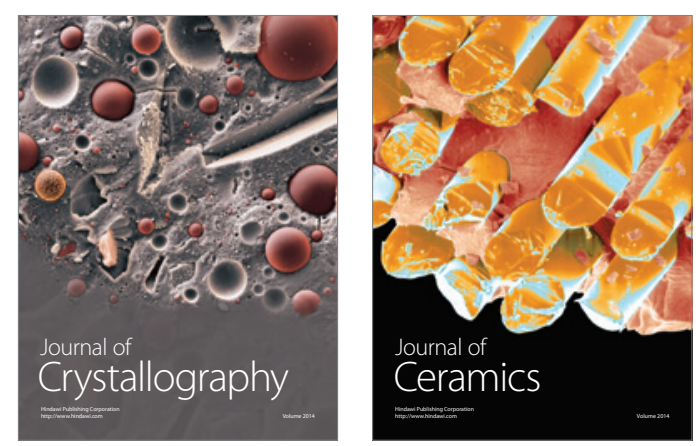
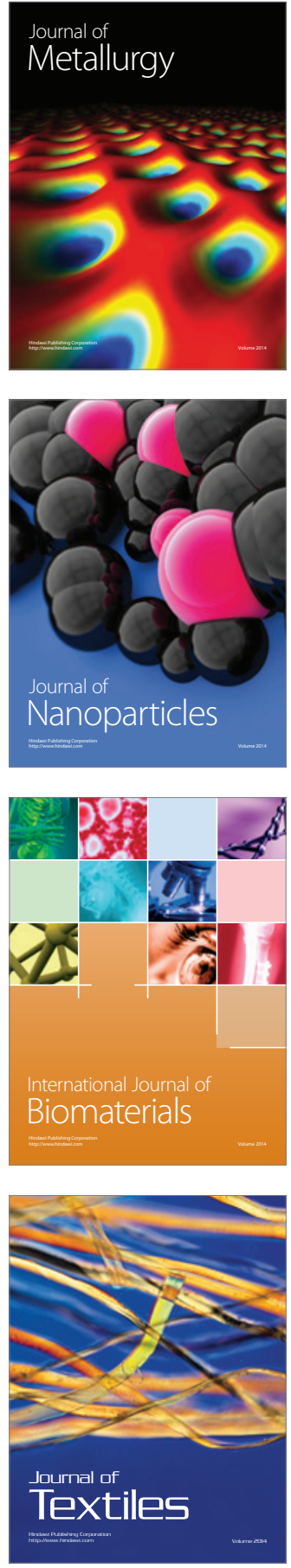